\title{
Modelos de tramas de simetria mineral de rochas do embasamento cristalino aplicados ao padrão de fraturamento do embasamento e de bacias sedimentares do tipo rifte. A Bacia de Camamu, Bahia, Brasil
}

\author{
Luiz César Corrêa-Gomes ${ }^{1,2}$, Thiago Freitas Lopes Conceição ${ }^{3}$, Idney Cavalcanti da \\ Silva $^{4}$, Simone Cerqueira Cruz $^{5}$ \& Johildo Salomão Figueiredo Barbosa ${ }^{5}$
}

\begin{abstract}
Resumo Na Bacia do tipo rifte de Camamu, BC, E do estado da Bahia, Brasil, modelos ideais de tramas de simetria mineral são comparados com os padrões de orientação de medidas de: (i) 201 foliações principais $\left(\mathrm{S}_{\mathrm{p}}\right)$ e 538 lineações de estiramento mineral $\left(\mathrm{L}_{\mathrm{x}}\right)$ do embasamento cristalino e (ii) 2530 lineamentos estruturais extraídos de imagens de modelo digital de terreno e 12.421 planos de falhas e fraturas extensionais, obtidas no campo nas rochas do embasamento cristalino e nas sequências sedimentares encontradas na borda da bacia. Em termos de estruturas, observa-se que: (i) as principais famílias de falhas do embasamento e das bordas da $\mathrm{BC}$ são paralelas a subparalelas à foliação principal subvertical e as $\mathrm{L}_{\mathrm{X}}$ do embasamento, $\mathrm{N} 00^{\circ}$ a N30 $0^{\circ}$, e diagonais $\mathrm{N} 90^{\circ}$ e N120 $0^{\circ}$, (ii) uma combinação entre as orientações das extensões regionais (N-S/E-W e NE-SW/NW-SE) e as tramas minerais do embasamento, influenciou a geração das falhas $\mathrm{N} 00^{\circ}$ a $\mathrm{N} 30^{\circ}, \mathrm{N} 90^{\circ}$ e $\mathrm{N} 120^{\circ}$, (iii) as direções N-S e os mergulhos subverticias da $\mathrm{S}_{\mathrm{p}}$, tanto para $\mathrm{E}$ quanto para $\mathrm{W}$, devem ter facilitado a abertura do rifte durante a propagação, no Mesozoico, do Atlântico Sul e, onde a $S_{p}$ é sub-horizontal, as orientações da $L_{x}$ local ganham importância, desse modo, não somente as $S_{p}$, mas também as $L_{x}$ tiveram influência importante na geração da trama de fraturamento de borda da $\mathrm{BC}$, e (iv) a erosão de espessa camada crustal, que expôs litotipos de fácies granulito e o relaxamento litosférico relacionado, pode ter possibilitado a geração de planos e linhas de fraqueza nas rochas, que teriam sido reaproveitadas durante a fase de rifteamento. Em termos de tramas de fraturamento, observa-se uma combinação claramente controlada pela trama mineral das rochas do embasamento: (i) monoclínica a triclínica, a mais frequente, onde as relações entre superfícies S-C são menos estreitadas ou houve sobreposição de fases de deformação, e (ii) (pseudo)ortorrômbica, em zonas de cisalhamento de deformação muito intensa onde as $\mathrm{S}_{\mathrm{p}} \mathrm{e}$ as $\mathrm{L}_{\mathrm{X}}$ tendem a se paralisar. Desse modo, não somente os campos de tensão, mas também as tramas de simetria mineral das rochas do embasamento cristalino foram fatores importantes na construção das tramas de fraturamento do embasamento e da Bacia de Camamu.
\end{abstract}

Palavras-chave: padrão de fraturamento, bacias tipo rifte, tramas de simetria mineral, herança estrutural do embasamento.

\begin{abstract}
Models of mineral symmetry fabrics of basement rocks applied to fracturing pattern of basement rocks and rift-type sedimentary basins. The Camamu Basin, State of Bahia, Brazil. In the Camamu rift basin-CB, E of state of Bahia, idealized models of mineral symmetry fabrics are compared with orientation patterns of the: (i) 201 planes of principal foliation $\left(\mathrm{S}_{\mathrm{p}}\right)$ and 538 measures of stretching mineral lineation $\left(\mathrm{L}_{\mathrm{x}}\right)$ in basement rocks, and (ii) 2,530 structural lineaments terrain digital model images and 12,421 planes of faults and fractures. The principal structure observed were as follows: (i) fault/fracture sets are parallels to $\mathrm{N} 00^{\circ}-30^{\circ}$-trending regional foliations $\left(\mathrm{S}_{\mathrm{P}}\right)$, and orthogonal $\left(\mathrm{N} 90^{\circ}\right.$-trending) to diagonal $\left(\mathrm{N} 120^{\circ}\right.$-trending) to $\mathrm{S}_{\mathrm{p}}$ and $\mathrm{L}_{\mathrm{X}}$, (ii) a combination between regional extension (N-S/E-W and NE-SW/NW-SE) and country rock mineral symmetry fabric orientations facilitated the $\mathrm{N} 00^{\circ}$ - to $30^{\circ}$-, $\mathrm{N} 90^{\circ}$ - and $\mathrm{N} 120^{\circ}$-trending fault set formation, (iii) the N-S strike and subvertical E- and W-dips of the $\mathrm{S}_{\mathrm{p}}$ facilitated the continental split associated to the Mesozoic South Atlantic opening. Where $\mathrm{S}_{\mathrm{p}}$ was sub-horizontal $\mathrm{L}_{\mathrm{X}}$ becomes an important influence that "induced" fault propagation directions. So not only $S_{p}$ but a $S_{p}+L_{X}$ combination was important to geometric construction of the fracturing fabric at the western border of the $\mathrm{CB}$. Finally (iv) the lithospheric load release due to the erosion of the thick crustal layer that exposing granulite facies rocks may have resulted in the
\end{abstract}

\footnotetext{
1 - Departamento de Ciências Aplicadas, Centro Federal de Educação Tecnológica da Bahia, Salvador (BA), Brasil. E-mail: gomes@cefetba.br

2 - Departamento de Geologia, Instituto de Geociências, Universidade Federal da Bahia, Salvador (BA), Brasil.

E-mail: lccgomes@ufba.br, johildo@cpgg.ufba.br

3 - Departamento de Geofísica, Instituto de Geociências, Universidade Federal da Bahia, Salvador (BA), Brasil.

E-mail: thiagoflc@hotmail.com

4 - Pós-Graduação em Geologia, Instituto de Geociências, Universidade Federal da Bahia, Salvador (BA), Brasil. E-mail: idney25@ig.com.br

5 - Departamento de Geologia, Instituto de Geociências, Universidade Federal da Bahia, Salvador (BA), Brasil.

E-mail: simoneufba@gmail.com
} 
production of weakness planes and lines reactivated during rifting event. A combination of monoclinic-triclinic fracturing fabrics was observed where S-C shear planes were not to close or where polyphasic deformation history occurred and (pseudo) orthorhombic fabric was observed where $\mathrm{S}_{\mathrm{P}}$ and $\mathrm{L}_{\mathrm{X}}$ became subparallel under extreme mineral stretching and rotation. Consequently not only the far-field stress orientations but also the basement rocks mineral symmetry fabrics were crucial to the evolution of the basement and Camamu Basin's fracturing patterns.

Keywords: fracturing pattern, rift-type basins, mineral symmetry fabric, basement structural heritage.

INTRODUÇÃO Bacias do tipo rifte são descritas como calhas tectônicas longas e estreitas, não raramente relacionadas à presença de plumas mantélicas, geradas em ambientes tectônicos onde há estiramento litosférico, propagação de ramos de junções tríplices e rupturas de paleocontinentes (Allen \& Allen 2005). Os principias conjuntos de falhas que modelam as bacias do tipo rifte são as longitudinais, paralelas ao comprimento maior da bacia, e as transversais, correspondentes às falhas transferentes cujos strikes são paralelos à orientação da extensão regional. Na construção destas bacias e de seus sistemas de falhas-fraturas, um grande debate existe sobre as importâncias relativas das orientações dos campos de tensão regional e das estruturas (rúpteis e dúcteis) herdadas do embasamento. Desse modo algumas questões importantes das relações estruturais entre embasamento e bacias sedimentares do tipo rifte são: (i) qual foi a importância das tramas de simetria mineral herdadas do embasamento cristalino na construção e evolução dessas bacias? (ii) Como essas tramas de simetria influenciaram nas tramas de fraturamento basinal e do embasamento?

Para a primeira questão, a importância de estruturas antigas na construção e evolução de bacias tipo rifte tem sido mencionada há algum tempo por alguns autores (ver, p. ex., Milani \& Davison 1988, Magnavita 1993, Corrêa-Gomes et al. 2005a, Silva 2009), que destacaram o paralelismo entre as falhas de borda das bacias e as orientações das foliações metamórficas do embasamento proximal. Por outro lado, muito pouco aparece citado sobre como isso acontece, segundo quais parâmetros mecânicos e, com base em dados de campo, quais são as relações geométricas existentes entre as estruturas extensionais e as foliações e lineações minerais herdadas do embasamento.

Para a segunda questão, não raramente, os embasamentos cristalinos de bacias sedimentares são regiões de deformação polifásica marcadas pela presença de potentes feixes de zonas de cisalhamento antigas (contracionais e extensionais, com algum componente cinemático transcorrente) cujos arranjos de simetria das estruturas dúcteis mais encontrados são de três tipos (Paterson \& Weiss 1961, Twiss \& Moores 2006): os ortorrômbicos, mais simples, e os monoclínicos e os triclínicos, mais complexos. Essas zonas de cisalhamento representam descontinuidades mecânicas muito fortes cujas tramas de simetria mineral, em situações de deformação rúptil regional, podem influenciar na geração de zonas de falhas que posteriormente serão reaproveitadas na construção e evolução das bacias. Desse modo, se torna interessante comparar, em um mesmo local, os padrões de simetria das tramas dúcteis do embasamento com aqueles dos padrões de fraturamento observados tanto no embasamento proximal quanto nas unidades sedimentares encontradas nas bordas de bacias sedimentares.

Para esse tipo de estudo, a borda emersa da Bacia sedimentar mesozoica de Camamu - BC (Fig. 1) foi escolhida por apresentar: (i) em $60 \mathrm{~km}$ de extensão um grande número de afloramentos bem conservados e com fácil acesso por estradas pavimentadas, (ii) uma geometria de borda muito regular, orientada aproximadamente N-S, claramente relacionada a (iii) um forte controle estrutural do Orógeno paleoproterozoico Itabuna-Salvador-Curaçá (Barbosa \& Dominguez 1996), delineado por potentes zonas de cisalhamento dúctil, de cinemática sinistral, produzidas em fácies granulito a anfibolito alto, marcadas pela presença de dobras isoclinais a apertadas e superfícies S-C. Além das foliações principais $\left(\mathrm{S}_{\mathrm{P}}\right)$, também foi estudada a influência das lineações de estiramento mineral $\left(\right.$ as $\left.L_{X}\right)$ na montagem da arquitetura estrutural da BC. Isso se justifica pelo fato de ter sido notado em trabalhos de campo que, mesmo em situações onde a $\mathrm{S}_{\mathrm{p}}$ era sub-horizontal, falhas subverticais podiam ser produzidas com strikes paralelos e ortogonais aos das $\mathrm{L}_{\mathrm{X}}$ encontradas nas rochas. Para isso foram medidos 2.530 lineamentos a partir das imagens-dados SRTM - Shuttle Radar Topography Mission, 12.421 planos de fraturas e falhas (a grande maioria com cinemática normal associada) no embasamento cristalino e nas unidades sedimentares próximas às bordas da $\mathrm{BC}, 201$ planos de Foliação Principal $\left(\mathrm{S}_{\mathrm{p}}\right)$ e 538 lineações de estiramento mineral $\left(\mathrm{L}_{\mathrm{x}}\right)$. A diferença na quantidade de medidas de $\mathrm{S}_{\mathrm{P}}$ e $\mathrm{L}_{\mathrm{X}}$ deveu-se ao fato de que, em um mesmo plano de foliação, mais de uma medida de linhas minerais puderam ser feitas.

OBJETIVOS A partir das duas questões levantadas previamente os principais objetivos desse trabalho foram definir: (i) a influência de estruturas planares e lineares dúcteis e rúpteis herdadas do embasamento cristalino na construção geométrica da Bacia de Camamu, e (ii) as fábricas de simetria de fraturamento que podem ser observadas nessa bacia e relacioná-las às tramas dúcteis encontradas no embasamento, comparando-as com modelos de tramas de simetria mineral ideais.

MATERIAIS E MÉTODOS A sistemática de trabalho pode ser dividida em quatro partes. A primeira 


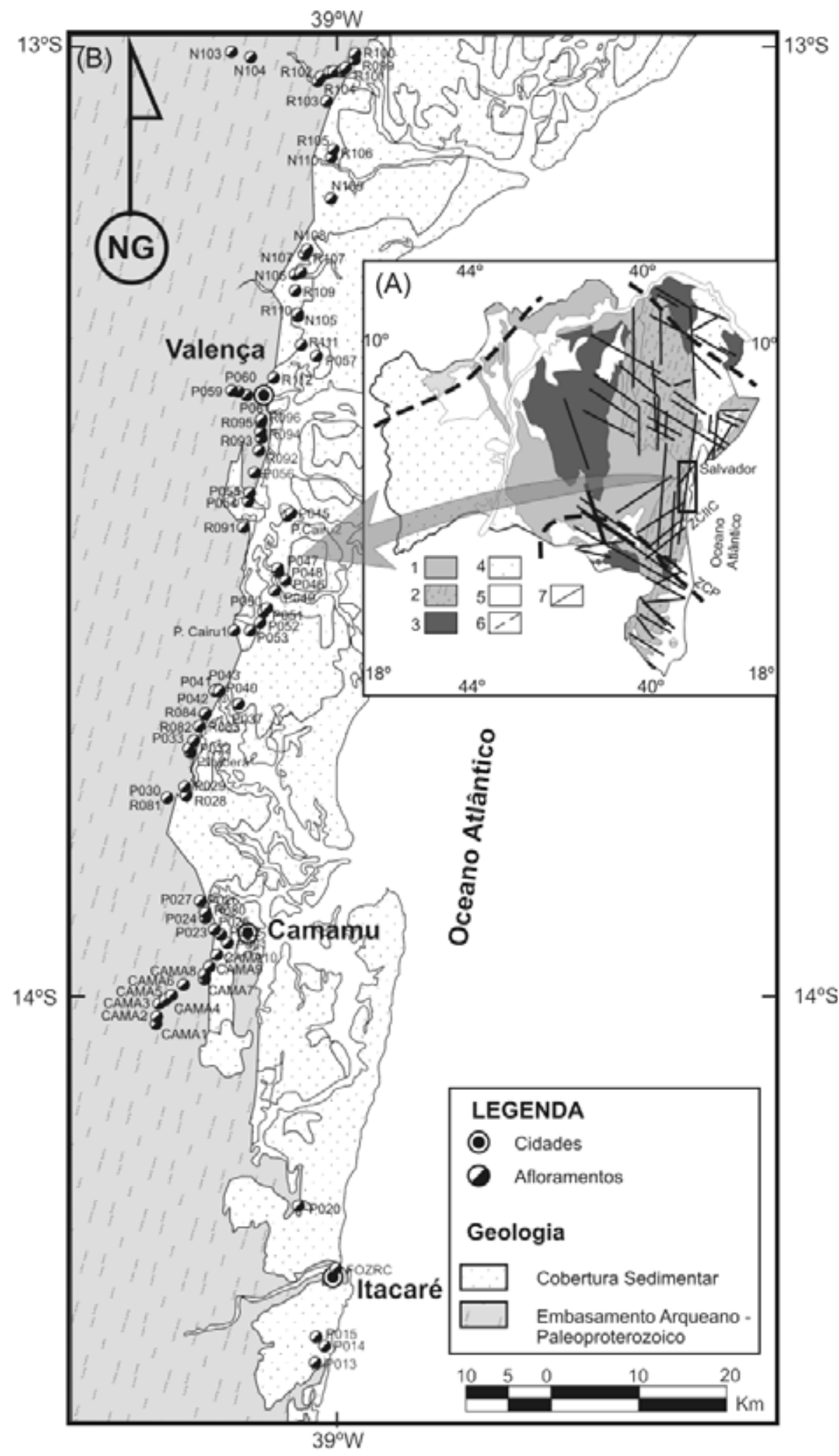

Figura 1 - (A) Mapa com a síntese das principais unidades geológicas do estado da Bahia, a localização da área estudada (retângulo na extremidade fina da seta) e a delimitação dos principais lineamentos estruturais regionais da porção oriental do Cráton do São Francisco: 1 - embasamento arqueano-paleoproterozoico; 2 - embasamento arqueano-paleoproterozoico proximal das bacias tipo rifte, com trama indicando a orientação da foliação principal regional; 3 - cobertura proterozoica; 4 - cobertura mesozoica; 5 - cobertura terciário-quaternária; 6 limite do Cráton do São Francisco e 7 - lineamento estrutural; ZCIIC - Zona de cisalhamento de Itabuna-Itaju do Colônia; ZCP - Zona de cisalhamento de Potiraguá. (B) Mapa de localização da Bacia sedimentar de Camamu e dos afloramentos visitados neste trabalho. Notar que apenas a borda Oeste dessa bacia está emersa (ambos os mapas, modificados de Barbosa \& Dominguez 1996 e Silva 2009). 
constou da delimitação de lineamentos estruturais traçados com base em contrastes topográficos de imagens georreferenciadas de modelo digital de relevo (SRTM - Shuttle Radar Topography Mission) para identificar as orientações e os comprimentos dos principais lineamentos estruturais que aparecem na área estudada. Desse modo, esses lineamentos tiveram seus azimutes e comprimentos medidos e plotados em diagramas de rosetas de frequência de orientação e de comprimento acumulado, em intervalos de pétalas de $10^{\circ} \mathrm{em} 10^{\circ}$.

A segunda consistiu da realização de trabalhos de campo ao longo do embasamento da borda oeste desta bacia. Nestes trabalhos foram coletados dados da direção e mergulho de falhas/fraturas e foliações principais $\left(\mathrm{S}_{\mathrm{p}}\right)$ e de direção e caimento de lineações de estiramento mineral $\left(\mathrm{L}_{\mathrm{x}}\right)$ e de atitudes de falhas e fraturas do embasamento proximal e dos litotipos sedimentares na borda da bacia.

$\mathrm{Na}$ terceira, as informações de estruturas de cada afloramento foram transferidas para bancos de dados e plotadas em redes estereográficas igual-área (SchmidtLambert), como pólos e linhas, com obtenção de curvas de isofrequência e rosetas de direção, de mergulho e de caimento (de $10^{\circ} \mathrm{em} 10^{\circ}$ ), com uso do software StereoNet (Duyster 2000), para uma melhor visualização das orientações mais marcantes.

Por fim realizou-se a análise e interpretação destes diagramas, comparando os dados de campo com modelos geométricos de tramas de simetria mineral.

GEOLOGIA REGIONAL A área de estudo está inserida no domínio tectônico da borda leste do Cráton do São Francisco (Almeida 1977). Os dois principais conjuntos tectônicos da área estudada são: (i) o Orógeno Itabuna-Salvador-Curaçá - OISC (Barbosa \& CorrêaGomes 2003), que representa o embasamento cristalino e passou por complexa história de evolução tectônica polifásica, e (ii) a Bacia mesozoica de Camamu - BC. A seguir, serão apresentados as estruturas regionais e os principais eventos tectônicos envolvidos nas suas formações e evoluções.

O Embasamento Cristalino O OISC é representado, na área pesquisada, pelo Cinturão paleoproterozoico Itabuna (Barbosa \& Dominguez 1996, Barbosa \& Corrêa-Gomes 2003, Barbosa \& Sabaté 2004) composto por enderbitos a charnoenderbitos com estruturas planares orientadas próximas de $\mathrm{N} 10^{\circ} \mathrm{e}$ mergulhos subverticais, tanto para NW quanto para SE. Nessa área, pelo menos, três fases deformacionais podem ser definidas, todas nas fácies granulito a anfibolito alto (Barbosa et al. 2005, Corrêa-Gomes et al. 2005a) (Fig. 2):

(i) a $F_{n}$ associada a estruturas planares sub-horizontais com lineações minerais de alto rake, muito pouco preservadas;

(ii) a $\mathrm{F}_{n+1}$ associada à presença de rampas frontais de cisalhamento que deformaram a $S_{n}$, com formação de dobras isoclinais recumbentes com planos axiais $\left(\mathrm{S}_{\mathrm{n}+1}\right)$ e eixos sub-horizontais, estes últimos caracterizados por lineações de estiramento mineral do tipo dip-slip e marcadores cinemáticos (e.g. foliações S-C e assimetria de mantos de porfiroclastos $\sigma$ e $\delta$ ) indicativos de movimentação reversa com transporte de massa de E para W;

(iii) a fase posterior $\left(\mathrm{F}_{\mathrm{n}+2}\right)$, interpretada como de evolução progressiva ao evento $\left(\mathrm{F}_{\mathrm{n}+1}\right)$, gerou, em zonas de high strain, dobras apertadas associadas a rampas laterais, com planos axiais subverticias $\left(\mathrm{S}_{\mathrm{n}+2}\right)$ com orientação geral $\mathrm{N}^{\circ} 0^{\circ}$ a $\mathrm{N} 10^{\circ}$ e eixos/lineações de baixo caimento. Estas lineações são do tipo strike-slip, embora localmente possam ser notadas torções que as inclinam. A essa segunda fase se relaciona uma transcompressão de cinemática regional sinistral que dobrou a superfície anterior $\left(\mathrm{S}_{\mathrm{n}+1}\right)$, de modo fechado a isoclinal. Nas etapas tardias da segunda fase, outra subfase $\left(\mathrm{F}_{\mathrm{n}+2}\right)$ pode ser notada, apesar de apresentar grau de penetratividade mais fraco que as anteriores. Esta é marcada pela presença de zonas de cisalhamento sinistrais, subverticais, subparalelas aos planos axiais da $\mathrm{S}_{\mathrm{n}+2}$ constituindo também lineações tipo strike-slip, podendo localmente evoluir até a transposição das estruturas anteriores. Assim, a deformação paleoproterozoica resultou em uma forte foliação milonítica, orientada $\mathrm{N}_{0} 0^{\circ}$ a $\mathrm{N} 10^{\circ}$, com mergulhos subverticais principalmente para Este e, subordinadamente, para W, cuja dominância de frequência pode variar localmente.

Posteriormente, no limite Mesoproterozoico-Neoproterozoico ( $c a$. 1,0 Ga), ocorreu a intrusão de enxames de diques máficos tholeiíticos, relacionada a um domeamento litosférico que afetou as, hoje, porções proximais costeiras atlânticas do Brasil e da África (Corrêa-Gomes et al. 1996). No lado brasileiro dois enxames filonianos se destacaram: o de Salvador, cujos filões se orientaram preferencialmente $\mathrm{N} 120^{\circ-}$ $-140^{\circ}$ e o de Ilhéus - Olivença, com orientações entre $\mathrm{N} 90^{\circ}$ e $\mathrm{N} 120^{\circ}$. No Neoproterozoico $(0,7-0,5 \mathrm{Ga})$, ocorreu uma sucessão de eventos magmáticos ligados à formação da Província Alcalina do Sul da Bahia, composta por sienitos e enxames de diques máficos e félsicos alcalinos (Conceição \& Otero 1996). A estes eventos associam-se as formações das Zonas de cisalhamento de Itabuna-Itaju do Colônia (orientada $\mathrm{N} 45^{\circ}$ ) e de Potiraguá (orientada $\mathrm{N} 120^{\circ}$ ). Como poderá ser notado, essas orientações são recorrentes no decorrer da evolução geológica da borda leste do Cráton do São Francisco no estado da Bahia.

A Bacia de Camamu A BC apresenta uma orientação geral $\mathrm{N} 00^{\circ}-\mathrm{N} 10^{\circ}$ e se estende desde a cidade de Itacaré, passando por Camamú, até as proximidades de Valença. Separada do rifte Recôncavo-Tucano-Jatobá pela Falha da Barra, a BC faz parte do sistema de bacias do tipo rifte geradas no Mesozoico, durante a divisão dos continentes africano e sul-americano tendo desempenhado papel importante na abertura e evolução do oceano Atlântico Sul. Exatamente no seu limite norte, o rifte, evoluindo de sul para norte, bifurcou-se, desenvolvendo o rifte do sistema Recôncavo-Tucano-Jatobá, 

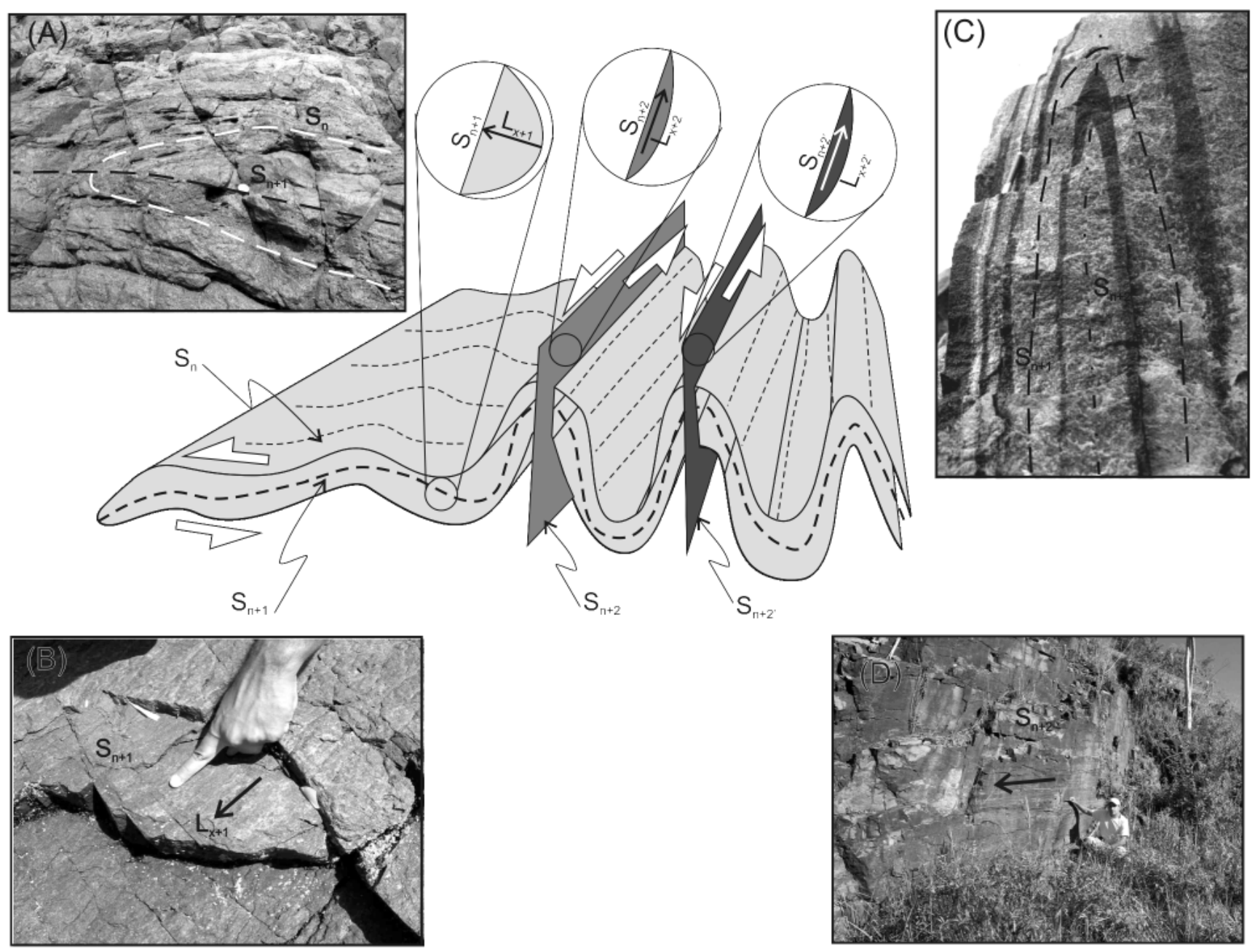

Figura 2. Esquema tridimensional e fotografias de campo mostrando as relações espaciais dip-slip (fotografias $A$ e B) e strike-slip (fotografias $C$ e D) entre as $S_{P}$ e as $L_{X}$ das estruturas impressas pelas fases tectônicas que afetaram o Orógeno Itabuna-Salvador-Curaçá na área estudada. Notar em (B) as fraturas ortogonais às $L_{X}$ No esquema 3-D aparece a indicação da orientação das superficies e lineações minerais, em rede estereográfica igual-área, Schmidt-Lambert, no hemisfério inferior. As setas nos grandes círculos indicam a cinemática do bloco ausente (missing block) de cada fase, ou subfase, tectônica (modificado de Corrêa-Gomes et al. 2005a).

abortado no Eoaptiano, e o rifte Sergipe-Alagoas, no qual efetivamente se propagou a ruptura onde o oceano Atlântico Sul foi implantado (Caixeta et al. 2007). As suas sequências sedimentares compreendem sedimentos jurássicos da fase pré-rifte, evoluindo para sequências de preenchimento dos riftes eocretáceos e culminando com a sedimentação marinha. Em termos de ambientes sedimentares (Caixeta et al. 2007), a fase pré-rifte foi dominada por sedimentação costeira e de supramaré, lacustre e desértica compondo a Formação Afligidos, a fase rifte precoce foi marcada por sedimentações lacustre raso, fluvial e eólica, sendo representada pelo Grupos jurássico Brotas e eocretáceo Santo Amaro, na fase rifte eocretácea dominou a sedimentação em ambientes fluvio-eólico-lacustre resultando na formação dos Grupos Almada e Camamu (porções basais), evoluindo nas fases pós-rifte e drift para ambientes marinho restrito a marinho pleno que representam os Grupos Camamu (porções de topo) e Espírito Santo.
A evolução tectônica associada à geração desses riftes pode ter sido fortemente influenciada pela presença de anomalias termais, superfícies de destacamento e zonas de armadilhamento de magma (Asmus \& Porto 1980, Ussami et al. 1986, Castro Jr. 1987), que podem ter, localmente, causado soerguimento crustal e acelerado as taxas de erosão e de descompressão litosférica.

Levantamentos de campo permitiram identificar vários padrões de orientação de planos de falha e fratura e de campos de tensão na área de influência da Bacia de Camamú (Corrêa-Gomes et al. 2005a, Silva 2009), tanto no embasamento quanto dentro da BC. Esses lineamentos podem também ser observados no mapa geológico do estado da Bahia (Fig.1, Barbosa e Dominguez 1996). Os principais sistemas de falhas são: $\mathrm{N} 00^{\circ}-10^{\circ}, \mathrm{N} 40^{\circ}-50^{\circ}, \mathrm{N} 120^{\circ}-140^{\circ}$ e $\mathrm{N} 90^{\circ}-100^{\circ}$. O $\mathrm{N}-\mathrm{S}$ é correspondente ao comprimento maior da $\mathrm{BC}$ e é paralelo à foliação principal regional do embasamento cristalino, o NE-SW é paralelo ao sistema de falhas 
da Zona de cisalhamento de Itabuna-Itaju do Colônia, o NW-SE aos traços do sistema de falhas da Zona de cisalhamento de Potiraguá e o E-W é ortogonal ao comprimento maior da BC. Em campo, as duas últimas orientações representam as falhas transferentes da Bacia de Camamu e mostram a importância dos lineamentos estruturais, ortogonais e diagonais ao eixo da $\mathrm{BC}$, na sua formação.

Quanto aos campos de tensão, os principais padrões de orientação do $\sigma_{1}$, com respeito ao comprimento maior da BC são (Corrêa-Gomes et al. 2005a, Silva 2009):

(i) paralelos e ortogonais, que poderiam estar relacionados à carga flexural de sedimentos, ao ressalto elástico de falhas de borda, à canalização de tensão de modo paralelo à calha da bacia, aos contrastes de densidade e de resistência mecânica entre a crosta oceânica e a crosta continental, e a força de empurrão da dorsal meso-oceânica, e

(ii) diagonais, com orientações NW-SE e NE-SW, que poderiam ser resultado da perturbação local de tensão por reativação de falhas antigas, da força de direcionamento de migração da placa tectônica ou ainda ser forças resultantes da interação local de duas ou mais tensões de $1^{\text {a }}$ (escala regional) e $2^{\text {a }}$ (escala local) ordens (Zoback 1992).

Esses dados de campos de tensão reforçam as observações de Magnavita (1992, 1993) e Magnavita et al. (2005) que indicam uma sequência de extensões E-W durante o rifteamento inicial e NW-SE no rifteamento final, para o sistema de bacias do Recôncavo-Tucano-Jatobá, vizinho a norte da Bacia de Camamu. Por outro lado, Destro (2002) e Destro et al. (2003a, b) observam a possibilidade de haver extensão longitudinal nestas bacias, marcada pela presença de falhas de alívio, cujos planos apresentam orientações ortogonais a transversais ao eixo maior da calha do rifte. Especificamente para a BC, Corrêa-Gomes et al. (2005a) e Silva (2009) sugerem que:

(i) as fases tectônicas precoces da BC foram marcadas por uma extensão tridimensional ortorrômbica (equivalente a uma tração triaxial) com todas as falhas apresentando cinemática normal e $\sigma_{1}$ verticais e $\sigma_{2}$ e $\sigma_{3}$ horizontais, estes dois com magnitudes próximas, $\mathrm{e}$

(ii) nas fases tectônicas finais o $\sigma$ foi horizontal associado a extensões NE-SW e NW-SE ortogonais entre si e contemporâneas, relacionadas às falhas transextensivas que aparecem marcadas nas coberturas terciário-quaternárias, indicando alguma reativação mais recente.

A alternância de orientações locais NW-SE/NE-SW do tensor máximo principal da fase transcorrente e a frequência de ocorrência de inversão de orientação do $\sigma_{1}$ são indicativas de que os mecanismos geradores dos campos de tensão ocorreram em pulsos (Corrêa-Gomes et al. 2005a, Silva 2009).

LINEAMENTOS ESTRUTURAIS EXTRAIIDOS DE IMAGENS SRTM Na figura 3 aparecem os lineamentos estruturais da área de influência da Bacia de Camamu extraídos das imagens de modelo digital de relevo (SRTM). A observação do diagrama de rosetas de direção de lineamentos (Fig. 3a) mostra um total de 2.530 linhas medidas com direções mais marcantes em $\mathrm{N} 00^{\circ}-10^{\circ}, 353$ medidas ou $13,95 \%$ do total, $\mathrm{N}^{\circ} 0^{\circ}-50^{\circ}$, 343 medidas ou $13,56 \%$ do total e N30 $-40^{\circ}, 276$ medidas ou $10,91 \%$ do total. Também são dignas de nota as orientações entre $\mathrm{N} 120^{\circ}$ e $140^{\circ}$. Quando são levados em consideração os comprimentos dos traços das estruturas percebe-se que as orientações próximas a N-S obtêm um aumento de importância por se tratarem dos lineamentos mais longos da área.

\section{PRINCIPAIS ORIENTACÕES DE FALHAS-} FRATURAS OBTIDAS NO CAMPO A figura 4 registra os dados das atitudes de 12.421 planos de falhas e fraturas obtidas no campo na seguinte ordem de apresentação de diagramas:

(i) rosetas de orientação de strikes, no qual as direções mais importantes são $\mathrm{N} 00^{\circ}-10^{\circ}$, com 1.748 medidas ou $14,07 \%$ do total, $\mathrm{N} 10^{\circ}-20^{\circ}$, com 1.397 medidas ou $11,25 \%$ do total e $\mathrm{N} 20^{\circ}-30^{\circ}$, com 1.188 medidas ou $9,56 \%$ do total. É interessante notar que existe uma diminuição gradativa de frequências de direção no sentido das orientações $\mathrm{N} 00^{\circ}$ até $\mathrm{N} 50^{\circ}$, e que as orientações entre $\mathrm{N} 110^{\circ}$ e $\mathrm{N} 130^{\circ}$ aparecem com boa frequência também,

(ii) rosetas de sentido de mergulho, no qual pode ser notado que a grande maioria dos planos mergulha para Leste, ou seja, no sentido do interior da bacia, e

(iii) isodensidade de frequência (rede estereográfica igual-área, hemisfério inferior), onde a maioria absoluta dos planos apresenta mergulhos próximos de verticais, com máximo polar em N277\% $12^{\circ}$.

É válido sublinhar a presença de inúmeras falhas sub-horizontais entre os conjuntos rúpteis estudados, porém, a quantidade de planos subverticias foi tão grande que essa presença acabou diluída.

\section{PRINCIPAIS ORIENTAÇOES DE FOLIAÇÃO}

No campo, as foliações principais são representadas principalmente pelas superfícies $\mathrm{C}$, dos sistemas S-C. Na figura 5 , são mostrados os dados das orientações de 201 planos de foliações principais obtidas no campo, na forma de diagramas de:

(i) rosetas de direção nas quais as orientações principais são $\mathrm{N} 00^{\circ}-10^{\circ}$, com 57 medidas ou $28,4 \%$ do total, $\mathrm{N} 10^{\circ}-20^{\circ}$, com 45 medidas ou $22,4 \%$ do total e N $20^{\circ}-30^{\circ}$, com 29 medidas ou $14,4 \%$ do total,

(ii) rosetas de mergulho com as principais orientações mergulhando para Oeste e para Este, de modo quase que igualmente distribuído, e

(iii) isodensidade de frequência, onde se pode notar a verticalidade dos planos de foliação, com máximo de concentração de pólos em $\mathrm{N} 98^{\circ} / 09^{\circ}$, refletindo a presença de dobras isoclinais a apertadas empinadas, da fase $\mathrm{F}_{\mathrm{n}+2}$, ajustadas sobre uma superfície sub-horizontal gerada na Fase $\mathrm{F}_{\mathrm{n}+1}$. Porém, 


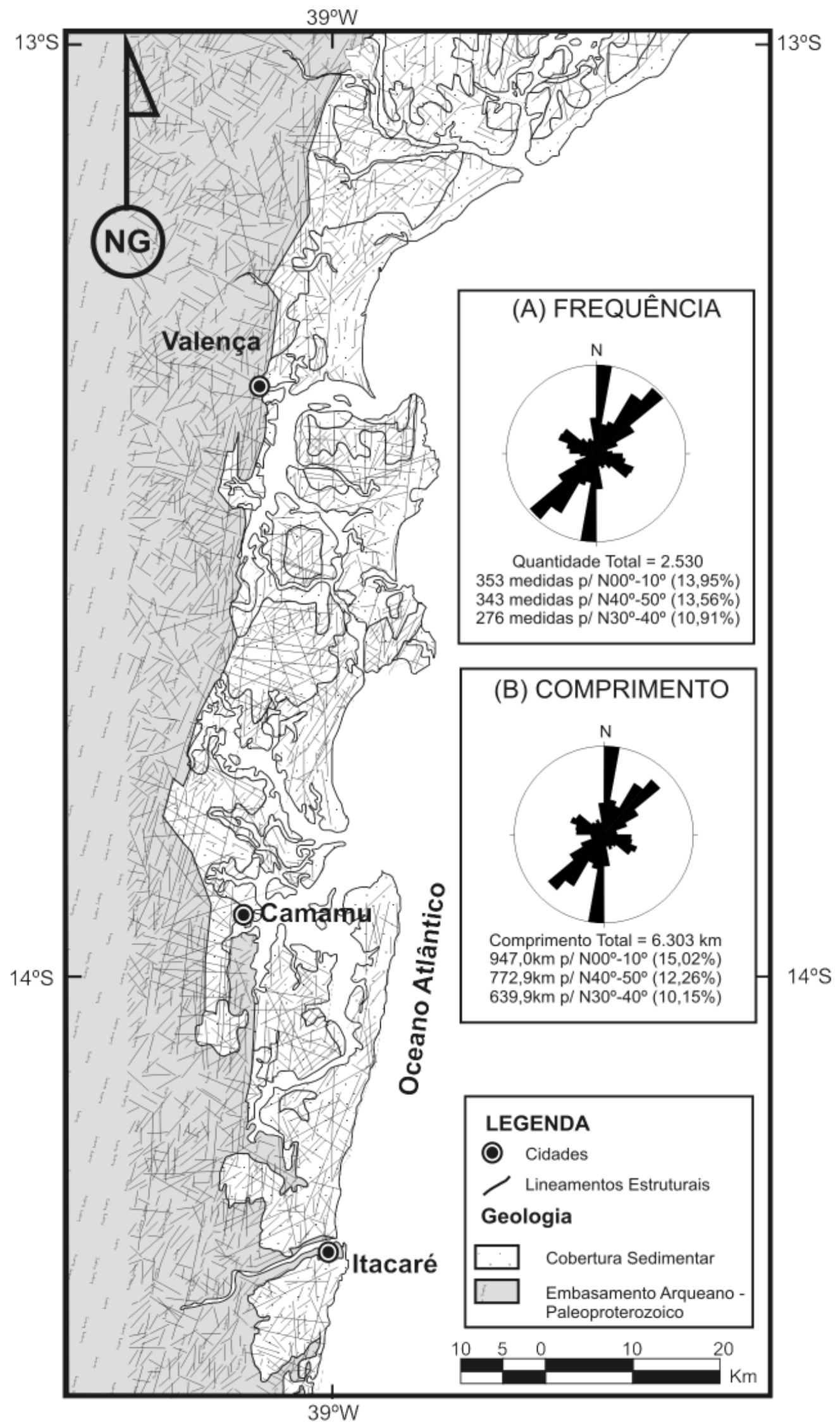

Figura 3 - Mapa geológico simplificado com o traçado dos 2.530 lineamentos estruturais extraídos de imagens de modelo de relevo (SRTM) para as áreas de influência da Bacia de Camamu e do embasamento proximal e diagramas em rosetas. Em (A) lineamentos por frequência e em (B) lineamentos por frequência $x$ comprimento (adaptado de Silva 2009). 


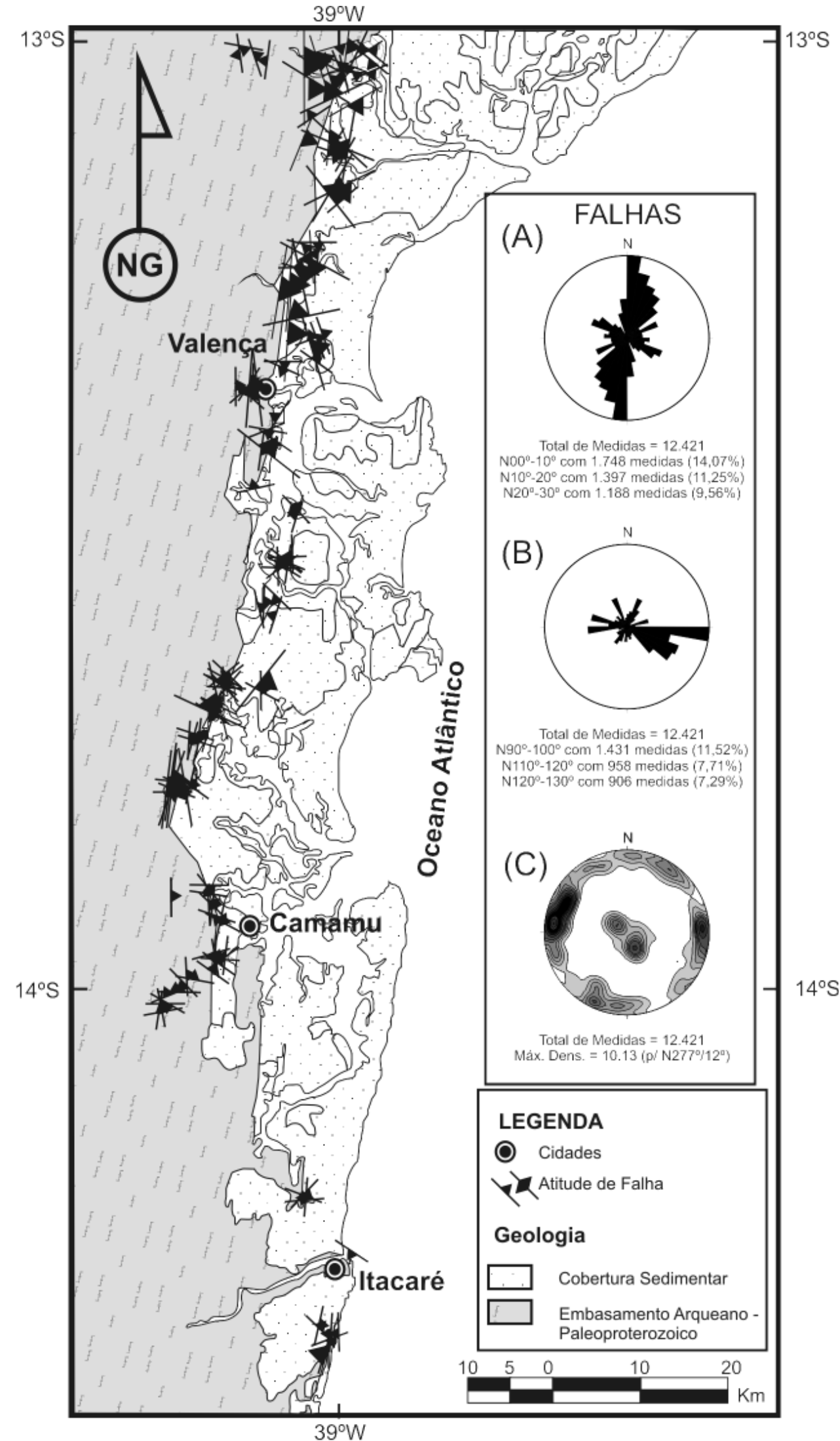

Figura 4 - Mapa geológico simplificado e diagramas em rosetas para 12.421 planos de falhas e fraturas obtidos no campo no embasamento proximal e nas unidades sedimentares próximas à borda da Bacia de Camamu. (A) rosetas de orientação de strikes dos planos, (B) rosetas de sentido de mergulho dos planos $e(C)$ diagramas de isodensidade de frequência de pólos, em rede estereográfica igual-área, hemisfério inferior. 


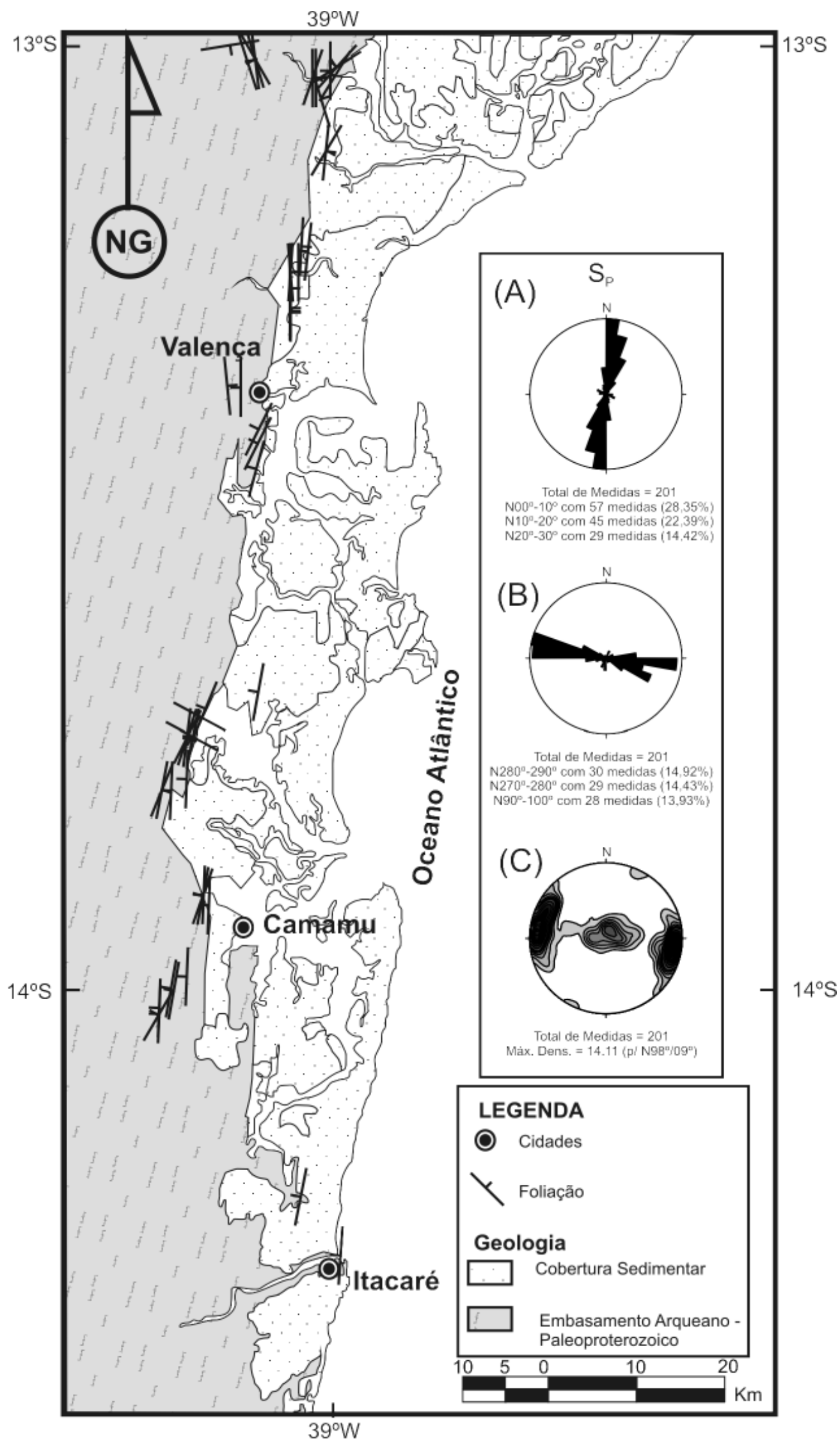

Figura 5 - Mapa geológico simplificado e diagramas em rosetas para 201 planos de foliação (SP), correspondentes em campo a superficies $C$, obtidos no embasamento proximal da Bacia de Camamu. (A) rosetas de orientação de strikes dos planos, (B) rosetas de sentido de mergulho dos planos e (C) diagramas de isodensidade de frequência de pólos, em rede estereográfica igual-área, hemisfério inferior. 
foliações sub-horizontais podem ser observadas com strikes próximos a N90 .

\section{PRINCIPAIS ORIENTAÇÕES DE LINEAÇÕES}

MINERAIS Na figura 6, são destacadas as principais orientações de 538 medidas de lineações de estiramento mineral, apresentadas na forma de diagramas de:

(i) rosetas de direção, nas quais as principais orientações são $\mathrm{N} 10^{\circ}-20^{\circ}$, com 164 medidas ou $30,5 \%$ do total, $\mathrm{N} 00^{\circ}-10^{\circ}$, com 102 medidas ou $18,96 \%$ do total e $\mathrm{N} 20^{\circ}-30^{\circ}$, com 92 medidas ou $17,10 \%$ do total,

(ii) rosetas de mergulho, com as principias orientações de caimento para NNE e menores incidências para SSE, e

(iii) isodensidade de frequência, no qual se pode notar a característica strike-slip de muito pequeno ângulo de rake das lineações em relação às foliações que as contêm e máximo de concentração de linhas em $\mathrm{N} 16^{\circ} / 12^{\circ}$.

MODELOS DE TRAMAS MINERAIS Existem várias classes de simetria associadas às tramas minerais de rochas (Paterson \& Weiss 1961, Twiss \& Moores 2006). Elas serão apresentadas a seguir da mais alta para a mais baixa ordem de simetria (Fig. 7):

(a) a isotrópica ou esférica: caracterizada por possuir um número infinito de planos espelhos e eixos rotacionais infinitos de simetria. Um exemplo típico é o da deformação volumétrica associada a pressões hidrostáticas e litostáticas sem deformação cisalhante. Os elipsoides de deformação aparecem como esferas perfeitas. Como resultado, as rochas com essa simetria são equigranulares e sem orientação cristalina preferencial (lineações ou foliações);

(b) a axial ou cilíndrica: caracterizada por um eixo de simetria rotacional infinito que é ortogonal a um plano espelho de simetria, o qual contém um número infinito de eixos rotacionais binários de simetria (paralelos aos raios da secção basal do cilindro). Os elipsoides de deformação aparecem com geometria de prolatos ou charutos. Uma rocha com esse tipo de simetria apresenta uma forte lineação mineral (tectonito L) sem foliação ou orientação planar importante. $\mathrm{O}$ eixo rotacional infinito de simetria binária é paralelo à lineação mineral.

(c) a ortorrômbico: correspondente à simetria de um bloco retangular com três lados ortogonais entre si e com três diferentes comprimentos, é caracterizada pela presença de três planos espelhos de simetria ortogonais entre si, os quais bissectam o bloco e são paralelos às suas três faces. O plano espelho de simetria e os três eixos binários de rotação são idênticos em orientação e posição aos planos e eixos de simetria dos elipsoides de deformação. Uma rocha que apresenta lineação contida na foliação é um exemplo de simetria ortorrômbica com três possíveis planos espelhos de simetria, um perpendicular à lineação e à foliação, outro paralelo à lineação e perpendicular à foliação e um terceiro paralelo às lineação e foliação. Esse tipo de simetria é mais comumente associado à tectonitos resultantes de deformação por cisalhamento puro ou a uma deformação extrema por cisalhamento simples.

(d) a monoclínica: é a simetria de um paralelepípedo rômbico produzido a partir de um cubo deformado por cisalhamento simples paralelo a uma das suas faces. É caracterizada pela presença de um plano de simetria espelho simples com um eixo de simetria binária perpendicular a esse plano. No caso do cubo cisalhado, o plano espelho de simetria é normal ao plano de cisalhamento e paralelo à direção de cisalhamento. Uma rocha com fábrica S-C tem uma simetria monoclínica com o plano espelho perpendicular à linha de intersecção dos planos $\mathrm{S}$ e $\mathrm{C}$.

(e) a triclínica: não apresenta planos espelhos ou eixos de simetria. Essa simetria normalmente é resultado da superposição de mais de uma fase de deformação nas quais elementos geométricos das diferentes fases são preservados. Nos casos em que deformações não são necessariamente relacionadas às orientações dos diferentes elipsoides de deformação podem não apresentar relações geométricas entre si. Assim, a trama resultante guardará elementos misturados de simetria e poderão constituir uma trama triclínica.

DISCUSSÕES Algumas considerações devem iniciar as discussões desse trabalho. A deformação relacionada à geração e à evolução da bacia estudada foi dominantemente rúptil típica de níveis crustais rasos. Isso implica que: (i) a facilidade de abertura pode ter sido fortemente controlada pela orientação da anisotropia dúctil $\left(\mathrm{S}_{\mathrm{p}}\right)$ mais importante, presente nas rochas, sendo a extensão ortogonal mais fácil que a paralela, (ii) as anisotropias mecânicas dúcteis e rúpteis pretéritas presentes no embasamento cristalino podem ter influenciado a orientação espacial de sistemas de fraturamento em uma proporção direta com respeito à intensidade da deformação e à penetratividade dessas estruturas, e (iii) a trama mineral planar, por ter maior continuidade espacial, pode ser localmente mais importante que a linear nesse controle. Essas considerações podem ser constatadas em inúmeros trabalhos clássicos e livros que abordam o tema "deformação experimental de rochas" (Paterson 1958, Heard 1960, 1963, Griggs \& Handin 1960, Griggs et al. 1960, Handin et al.1963, Griggs 1967, Donath 1970, Heard \& Raleigh 1972, Hobbs et al. 1976, Davis 1984, Nagaraj 1993, van der Pluijm \& Marshark 2004, Paterson \& Wong 2005, Twiss \& Moores 2006) e tornarão mais fácil entender as colocações que serão feitas a seguir.

Lineamentos estruturais obtidos em imagens de Modelo Digital de Relevo As principais orientações são coincidentes com aquelas obtidas por Corrêa-Gomes et al. (2005a) e Silva (2009), com marcante presença de 


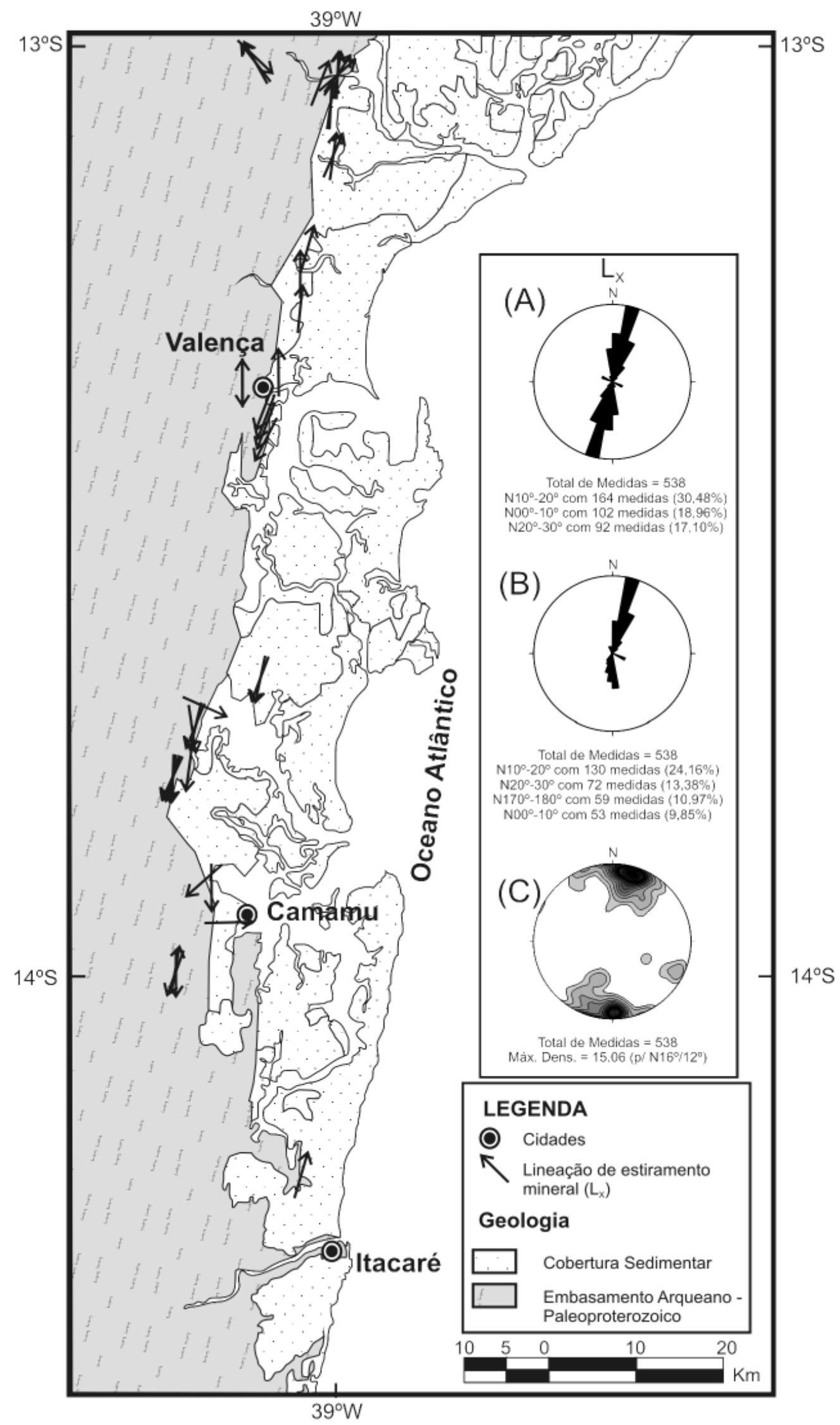

Figura 6 - Mapa geológico simplificado e diagramas em rosetas para 538 lineações de estiramento mineral obtidas no campo no embasamento proximal da Bacia de Camamu. (A) rosetas de orientação de strikes das lineações, (B) rosetas de sentido de caimento das linhas e $(C)$ diagramas de isodensidade de frequência de linhas em rede estereográfica igual-área, hemisfério inferior. 


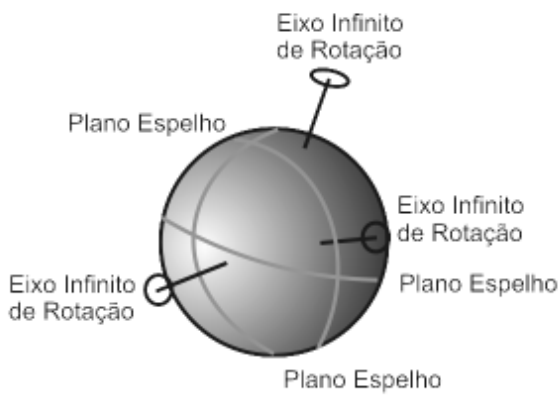

(A) Simetria Esférica

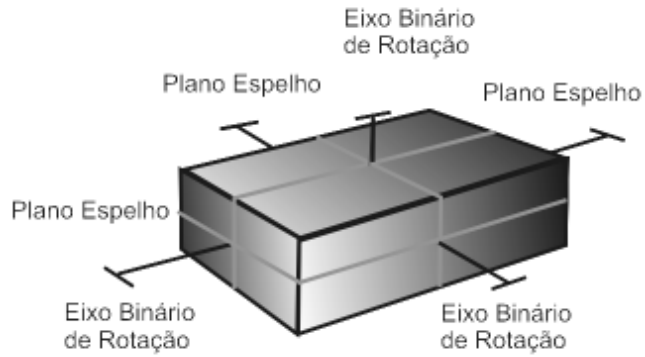

(C) Simetria Ortorrômbica

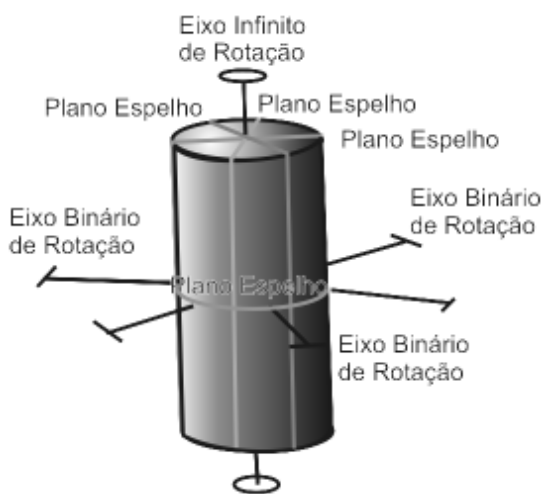

(B) Simetria Cilindrica

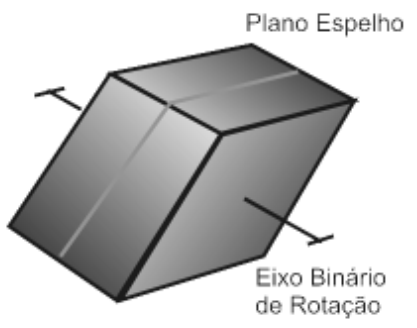

(D) Simetria Monoclínica

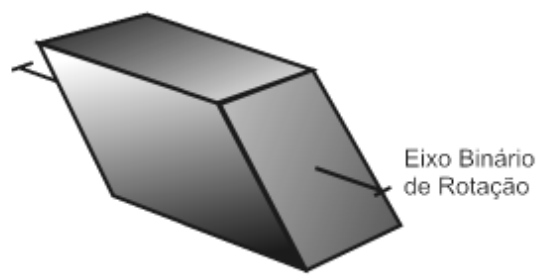

(E) Simetria Triclínica

Figura 7 - Principais tipos de simetria associadas às tramas minerais de rochas (Paterson \& Weiss 1961, Twiss \& Moores 2006). (A) isométrica ou esférica, (B) axial ou cilíndrica, (C) ortorrômbica, (D) monoclínica e (E) triclínica.

lineamentos próximos a N-S, considerados pelos autores como paralelos à $\mathrm{S}_{\mathrm{p}}$ do $\mathrm{OISC}, \mathrm{N} 90^{\circ}-100^{\circ}$, ortogonais a $S_{P}$ e $N 30^{\circ}-50^{\circ}$ e $N 120^{\circ}-140^{\circ}$, paralelos respectivamente aos sistemas de falhas e fraturas das Zonas de cisalhamento de Itabuna-Itaju do Colônia (orientada $\mathrm{N}^{\circ} 5^{\circ}$ ) e de Potiraguá (orientada N120) (ver Fig. 1).

Planos de falhas e fraturas obtidos no campo Existe uma boa correlação entre as orientações dos lineamentos estruturais obtidos das imagens SRTM e os dados de campo. Porém, enquanto os dados de lineamentos estruturais mostram uma separação clara entre as direções $\mathrm{N} 00^{\circ}-10^{\circ}$ e $\mathrm{N} 40^{\circ}-50^{\circ}$, os planos de falhas e fraturas obtidos no campo apresentam uma dispersão de direções, com frequência cada vez menor, entre as direções $\mathrm{N}^{\circ} 0^{\circ}$ até $\mathrm{N} 50^{\circ}$. Isso parece indicar que as falhas da zona de borda da $\mathrm{BC}$ alternaram preferência em acompanhar a orientação da $\mathrm{S}_{\mathrm{p}}$ ou de algum outro elemento estrutural importante localmente presente (a $\mathrm{L}_{\mathrm{x}}$ ?). Outro fato notável é que a grande maioria dos planos medidos ficou entre $\mathrm{N}_{0} 0^{\circ}$ e $\mathrm{N} 30^{\circ}$, enquanto que as orientações NE-SW e NW-SE apareceram representadas no campo de modo mais modesto. Das 12.421 medidas, para as direções entre $\mathrm{N} 00^{\circ}$ e $\mathrm{N} 30^{\circ}$ foram registradas 4.333 medidas, o que pode ter minimizado a importância de outras orientações de planos. Juntando as observações dos dados extraídos das imagens SRTM com os dos planos medidos no campo, nota-se que não somente as estruturas dúcteis, mas também estruturas rúpteis já existentes no embasamento podem ter sido reaproveitadas na instalação da BC. Esta possibilidade será verificada mais à frente. 
Foliações e Lineações Minerais obtidas no campo As orientações das foliações principais e lineações de estiramento mineral são fortemente indicativas de que houve um estreito relacionamento espacial entre essas estruturas. Em campo, nas bordas da Bacia de Camamu, a intensidade da deformação fica mais evidenciada quando, localmente, as $\mathrm{S}_{\mathrm{n}+2}$, representadas por faixas miloníticas com porfiroclastos-porfiroblastos, são transpostas pelas $\mathrm{S}_{\mathrm{n}+2}$, sendo reduzidas a milonitos de granulometria mais fina, resultando em uma trama de simetria que se aproxima de ortorrômbica com superfícies $\mathrm{S}-\mathrm{C}$ subparalelas. Em resumo, onde as superfícies S-C apresentam ângulos mais abertos, a tendência é de se observar tramas de simetria monoclínicas e triclínicas, e quando esses ângulos são mais apertados a tendência é de se observar uma trama próxima da ortorrômbica (ou pseudortorrômbica).

Nas figuras 5 e 6 aparecem os máximos de concentração polar das $\mathrm{S}_{\mathrm{p}}, \mathrm{N} 98^{\circ} / 09^{\circ}$ (implicando em um plano médio igual a $\mathrm{N} 08^{\circ} / 81^{\circ} \mathrm{NW}$ ) e das $\mathrm{L}_{\mathrm{X}}, \mathrm{N} 16^{\circ} / 12^{\circ}$. A pequena diferença angular $S_{P} \wedge L_{X}$ e as observações dos marcadores cinemáticos no campo revelam um cisalhamento sinistral com forte estiramento mineral, quase paralelizando os strikes das foliações com os das lineações minerais.

Regionalmente a maioria dos mergulhos da foliação principal é para Este. No caso do embasamento da $\mathrm{BC}$, existe certa tendência para Oeste, porém, mergulhos para Este são também frequentes. Isto pode ser interpretado de várias maneiras: ou localmente são encontrados flancos de dobras isoclinais mergulhando para lados opostos, ou a $\mathrm{S}_{\mathrm{p}}$ é representada localmente por uma superfície que sofreu torções gerando planos com mergulhos para lados opostos, ou ainda pode haver uma distribuição estreita de foliações estruturadas em flor.

Influência de estruturas do embasamento na geração de bacias sedimentares Ainfluência das estruturas herdadas do embasamento cristalino na construção e evolução de bacias tipo rifte brasileiras tem sido noticiada há algum tempo (e.g. Milani \& Davison 1988, Magnavita 1993, Corrêa-Gomes et al. 2005a, b, Silva 2009). Nesses trabalhos são feitas citações sobre o efeito de planos dúcteis (e.g. foliações metamórficas) e de zonas de cisalhamento rúpteis pré-existentes que são reaproveitadas pelos planos rúpteis das bacias e margens fendilhadas durante o processo de rasgamento paleocontinental. Dois exemplos clássicos da importância do arcabouço estrutural do embasamento de sistemas tipos rifte podem ser notados: (i) no braço continental africano do Rifte Este, que se propagando para SSW no sentido no alto do Lago Vitória, bifurca-se contornando uma porção cratônica mais espessa e, após ultrapassar esse núcleo, volta a unir-se em ramo único, e (ii) no nordeste brasileiro na propagação de sul para norte da Bacia de Tucano mudando para ENE na Bacia de Jatobá em consonância com a orientação da Província Borborema.

Por outro lado, normalmente bacias do tipo rifte formam longas e estreitas depressões cujas bordas são controladas por grandes falhas normais, sendo a extensão regional acomodada pela produção de falhas transferentes de strikes paralelos ao $\sigma_{3}$ regional (Clifton et al. 2000, Allen \& Allen 2005), ou seja, a orientação do campo remoto de tensão (far-field stress) é considerada também como uma importante influência na construção 3-D do arcabouço de falhas destas bacias. É interessante notar que, no caso de modelos analógicos de formação de bacias, é usual que o material utilizado para mimetizar o embasamento seja representado por materiais de resposta mecânica a deformação mais simples, do tipo blocos de argila e de areia (clay-sand boxs) e de silicone, visando facilitar a interpretação das estruturas geradas nos experimentos. Porém, a propagação de fraturas em um determinado meio depende de inúmeros parâmetros, entre eles, a pressão de fluidos, a pressão de confinamento, a temperatura ambiente, o tipo de rocha, o grau de anisotropia da rocha quebrada, a relação angular entre a fratura produzida e a orientação interna da rocha, a taxa de deformação etc., (Heard \& Raleigh 1972, van der Pluijm \& Marshark 2004, Paterson \& Wong 2005, Twiss \& Moores 2006).

Dentro desse universo de possibilidades, para os fins desse trabalho, algumas lacunas importantes podem ser observadas em trabalhos que abordam o tema, entre elas a ausência de:

(i) comparações, com base em dados de campo, entre as estruturas dúcteis (foliações e lineações principais $\mathrm{S}_{\mathrm{P}} \mathrm{e} \mathrm{L}_{\mathrm{X}}$ ) e os planos da deformação rúptil,

(ii) comparações entre as geometrias de tramas de deformação mineral e das fraturas relacionadas, e

(iii) discussões sobre a influência das $L_{X}$ nos processos de fraturamento das bacias.

A influência das $\mathrm{S}_{\mathrm{p}}$ paleoproterozoicas do OISC e de zonas de cisalhamento rúpteis neoproterozoicas, tais como a Zona de cisalhamento de Itabuna-Itajú do Colônia, já havia sido discutida, respectivamente, nas gêneses das Bacias de Camamu e Almada (Corrêa-Gomes et al. 2005a, b, Silva 2009). Estes autores consideram que as orientações dúcteis N-S do embasamento foram fortes controladoras da geometria da $\mathrm{BC}$, enquanto que a geometria da Bacia de Almada teria sido mais construída sob o condicionamento pelas orientações $\mathrm{N}^{\circ} 5^{\circ}$ das falhas da Zona de cisalhamento de Itabuna-Itaju do Colônia. Além das orientações $\mathrm{N}-\mathrm{S}$ e E-W, também ocorrem na $\mathrm{BC}$ as orientações $\mathrm{N} 45^{\circ}$ e $\mathrm{N} 120^{\circ}$, sugerindo que, mesmo antes da formação da bacia, a anisotropia dúctil do embasamento já poderia ter influenciado na geração e orientação de estruturas rúpteis regionais.

Além das orientações planares, a atenção voltou-se também para o papel das lineações de estiramento mineral $\left(\right.$ as $\left.L_{X}\right)$. Isso se justifica pelo fato de ter sido notado no campo que, em situações onde a $S_{p}$ era sub-horizontal, falhas subverticais podiam ser produzidas com strikes paralelos e perpendiculares aos das $\mathrm{L}_{\mathrm{X}}$ encontradas nas rochas. Desse modo, começou-se a suspeitar que a trama das famílias de falhas/fraturas associadas às bacias sedimentares teria sido influenciada, também, pela trama linear encontrada nas rochas do 
embasamento cristalino proximal às bacias. Além disso, notou-se que o grau de penetratividade dessas estruturas é fundamental para definir a força da herança das mesmas na geração de novas estruturas rúpteis.

Em uma rápida revisão do que ocorreu na área da Bacia de Camamu, deve ser lembrado que as estruturas do embasamento que hoje afloram representam as raízes milonitizadas de um grande orógeno, o OISC, produzido no Paleoproterozoico ( $\mathrm{ca}$. 2,1-2,0 Ga), cuja erosão pode ter removido até $30 \mathrm{~km}$ de coluna de rochas sotopostas expondo litotipos de fácies granulito (Barbosa \& Dominguez 1996, Barbosa \& Sabaté 2004). A remoção dessa coluna de rochas certamente gerou uma descompressão litosférica que preparou o terreno para facilitar a propagação axial, de Sul para Norte, do Atlântico Sul e geração das bacias tipo rifte brasileiras relacionadas à poderosa extensão que viria a acontecer no Mesozoico. Na separação paleocontinental, em termos mecânicos, o campo remoto de tensão (far-field stress) aproveitou locais de mais fácil propagação e encontrou em crostas mais finas, nas zonas miloníticas e nas falhas antigas um ambiente francamente favorável, mesmo em se tratando de uma porção cratônica. Dessa maneira, as tramas de simetria mineral originais dos litotipos presentes podem ter influenciado os padrões de fraturamento relacionados aos riftes locais, mesmo antes do rifteamento ocorrer.

\section{Modelos Geométricos de Tramas de simetria} mineral e de Fraturamento $\mathrm{O}$ termo "Trama de Fraturamento" deve ser entendido aqui como o arranjo tridimensional de planos de falhas e fraturas associado a um ou mais eventos de quebramento de uma rocha e tem semelhante significado geométrico de uma trama de simetria mineral. Em faixas intensamente milonitizadas, semelhantes àquelas observadas no Orógeno Itabuna-Salvador-Curaçá, três tipos de fábricas dúcteis são mais frequentemente encontradas (Paterson \& Weiss 1961): as ortorrômbicas, mais simples, e as monoclínicas e as triclínicas, mais complexas. Todas essas tramas de simetria mineral e suas correspondências rúpteis podem ser encontradas no embasamento proximal da BC (Fig. 8).

Para a geração de modelos geométricos das tramas minerais e das respectivas tramas de fraturamento é preciso levar em consideração as observações de campo, tais como: (i) as foliações são verticalizadas (a grande maioria) e sub-horizontais (menos frequentes) e as lineações minerais possuem baixo ângulo de caimento, (ii) as orientações dos planos e linhas são consequência de deformações reversas (relacionadas à $\mathrm{F}_{\mathrm{n}+1}$ ) e sinistrais (relacionadas às $\mathrm{F}_{\mathrm{n}+2}$ e $\mathrm{F}_{\mathrm{n}+2}$, ) e (iii) os planos de quebramento podem ser tanto paralelos quanto ortogonais às estruturas dúcteis planares (principalmente) e lineares. Desse modo, serão essas as situações a serem modeladas a seguir (Fig. 9). Também é necessário lembrar que cinemáticas sinistrais ou dextrais em planos verticais de cisalhamento são perfeitamente possíveis na natureza, porém em planos perfeitamente horizontais a determinação de cinemáticas normais ou reversas é bem mais difícil. Por isso nos modelos com $\mathrm{S}_{\mathrm{p}}$ horizontal a cinemática reversa deve ser considerada de modo meramente ilustrativo. Nas situações apresentadas, três planos fundamentais de fraturas são gerados: um longitudinal (LG), outro transversal (TR) e um terceiro basal (BS) à foliação principal. Em todos os casos, a produção de planos de fraturas dependerá da penetratividade das superfícies $\mathrm{S}-\mathrm{C}$ e das $\mathrm{L}_{\mathrm{x}}$.

Inicialmente pode-se imaginar uma situação hipotética na qual existe uma forte foliação milonítica vertical (superfície $\mathrm{C}$ ) orientada $\mathrm{N}-\mathrm{S}$ :

- considerando uma trama ortorrômbica, três planos de fraturas ortogonais entre si poderiam ser gerados: um longitudinal (LG) vertical paralelo à $S_{\mathrm{p}} \mathrm{e}$ à $\mathrm{L}_{\mathrm{x}}$ orientado $\mathrm{N} 00^{\circ} / \mathrm{V}$, outro vertical transversal (TR) ortogonal a $\mathrm{S}_{\mathrm{p}}$ e à $\mathrm{L}_{\mathrm{x}}$, orientado $\mathrm{N} 90^{\circ} / \mathrm{V}$ e um terceiro horizontal ou basal (BS) e ortogonal a $S_{p} e$ paralelo à $\mathrm{L}_{\mathrm{x}}$,

- para uma trama monoclínica sinistral com rotação de $30^{\circ}$ segundo um eixo vertical da $\mathrm{L}_{\mathrm{x}}$ em relação a $S_{p}\left(S_{p} / / L_{X}\right.$ no plano vertical e $S_{p}$ diagonal a $L_{x}$ no plano horizontal) além dos planos paralelos e ortogonais a $\mathrm{S}_{\mathrm{P}}(\mathrm{LG}, \mathrm{TR}$ e BS) da deformação ortorrômbica, dois outros planos podem ser gerados, um $\mathrm{N} 30^{\circ} / \mathrm{V}$ (paralelo aos planos XY das $\mathrm{L}_{\mathrm{X}}$ ) e $\mathrm{N} 120^{\circ} / \mathrm{V}$ (paralelo aos planos $\mathrm{YZ}$ das $\mathrm{L}_{\mathrm{X}}$ ),

- para uma trama triclínica, combinando cinemáticas sinistral e reversa com $30^{\circ}$ de rotação segundo eixos vertical e horizontal, além dos planos gerados na deformação monoclínica poderiam ser produzidos planos $\mathrm{N} 120^{\circ} / 30^{\circ} \mathrm{SW}$ (paralelos aos planos $\mathrm{XZ}$ das $\mathrm{L}_{\mathrm{X}}$ ) e $\mathrm{N} 120^{\circ} / 60^{\circ} \mathrm{NE}$ (paralelos aos planos $\mathrm{YZ}$ das $\mathrm{L}_{\mathrm{X}}$ ).

Para uma foliação milonítica horizontal:

- considerando uma trama ortorrômbica três planos de fraturas serão gerados: um horizontal (paralelo as $\mathrm{S}_{\mathrm{p}} \mathrm{e}$ $\mathrm{L}_{\mathrm{X}}$ ), um ortogonal às $\mathrm{S}_{\mathrm{P}}$ e $\mathrm{L}_{\mathrm{X}}$, orientado $\mathrm{N} 90^{\circ} / \mathrm{V}$, e outro ortogonal à $\mathrm{S}_{\mathrm{P}}$ e paralelo à $\mathrm{L}_{\mathrm{X}}$, orientado $\mathrm{N} 00^{\circ} / \mathrm{V}$,

- para uma trama monoclínica reversa, com rotação segundo um eixo horizontal da $L_{X}$ em relação a $S_{P}$ de $30^{\circ}\left(\mathrm{S}_{\mathrm{p}} / / \mathrm{L}_{\mathrm{x}}\right.$ no plano horizontal e $\mathrm{S}_{\mathrm{p}}$ diagonal a $\mathrm{L}_{\mathrm{x}}$ no plano vertical) além dos planos da deformação ortorrômbica, dois outros planos podem ser gerados, um N90\%30 $0^{\circ}$ (paralelo aos planos $\mathrm{XY}$ das $\mathrm{L}_{\mathrm{X}}$ ) e $\mathrm{N} 90^{\circ} / 60^{\circ} \mathrm{N}$ (paralelo aos planos $\mathrm{YZ}$ das $\mathrm{L}_{\mathrm{X}}$ ), e

- para uma trama triclínica, combinando cinemáticas reversa e sinistral, com $30^{\circ}$ de rotação segundo os eixos horizontal e vertical, além dos planos gerados na deformação monoclínica poderiam ser produzidos planos $\mathrm{N} 120^{\circ} / 30^{\circ} \mathrm{SW}$ (paralelos aos planos XY das $\mathrm{L}_{\mathrm{x}}$ ) e $\mathrm{N} 120^{\circ} / 60^{\circ} \mathrm{NE}$ (paralelos aos planos $\mathrm{YZ}$ das $\mathrm{L}_{\mathrm{x}}$ ).

Apesar dos modelos de tramas de fraturamento acima descritos estarem condicionados aos dados geométricos modelados, como estes estão relacionados ao paralelismo e ao perpendicularismo com as estruturas dúcteis planares e lineares, podem ser facilmente adaptados para outras orientações espaciais de estruturas. Quanto às estruturas dúcteis fica sugerido que: (i) no caso de uma extensão horizontal ortogonal a foliações verticais, a abertura paralela e $S_{\mathrm{P}}$ (seja ela uma superfície $\mathrm{S}$ ou $\mathrm{C}$ ) será facilitada e, provavelmente, terá preferência. Contudo, uma $\mathrm{L}_{\mathrm{x}}$ fortemente impressa pode alterar localmente essa predominância (ver Figs. 3 e 4), 
(A)

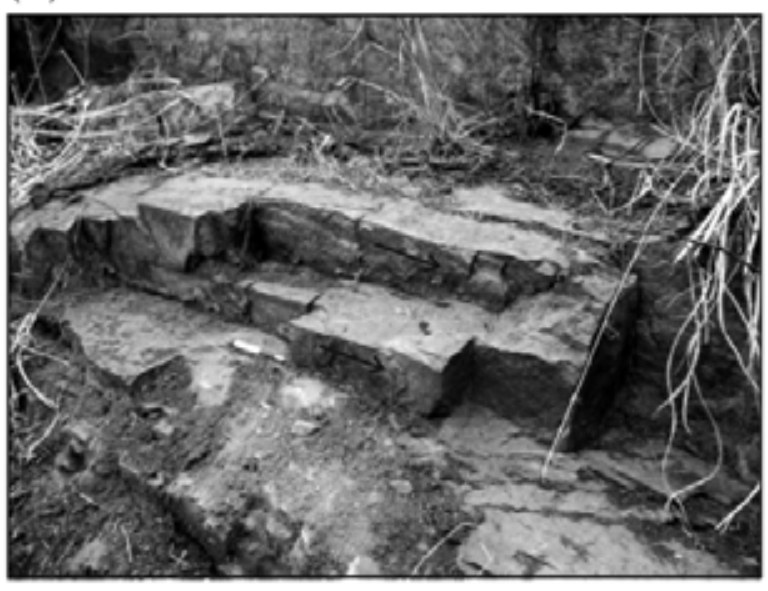

(B)

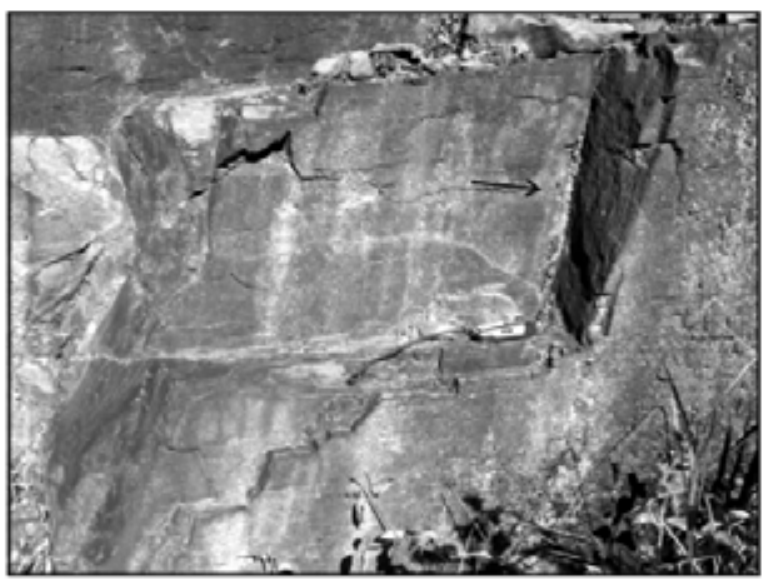

(C)

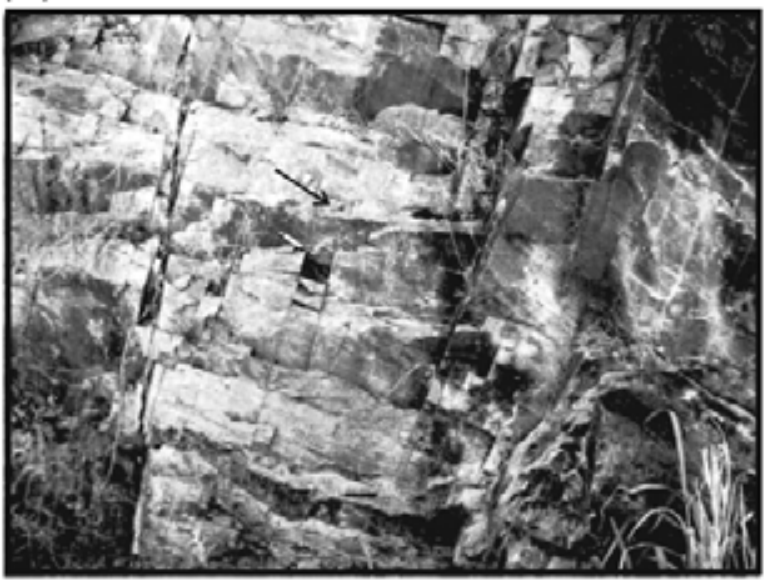

(D)

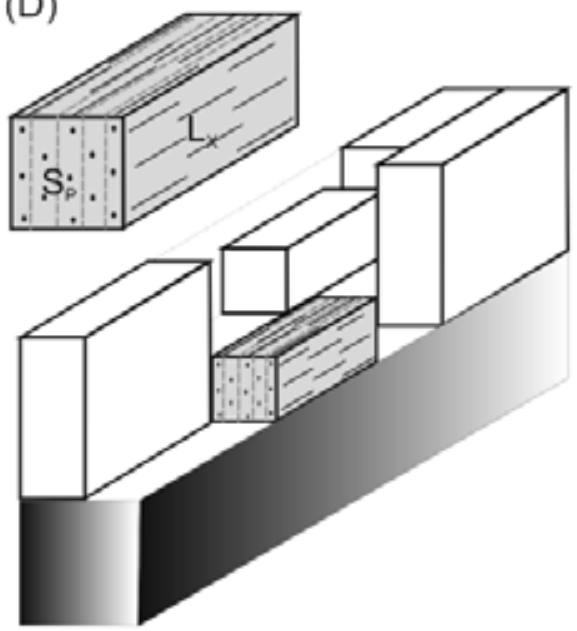

(E)

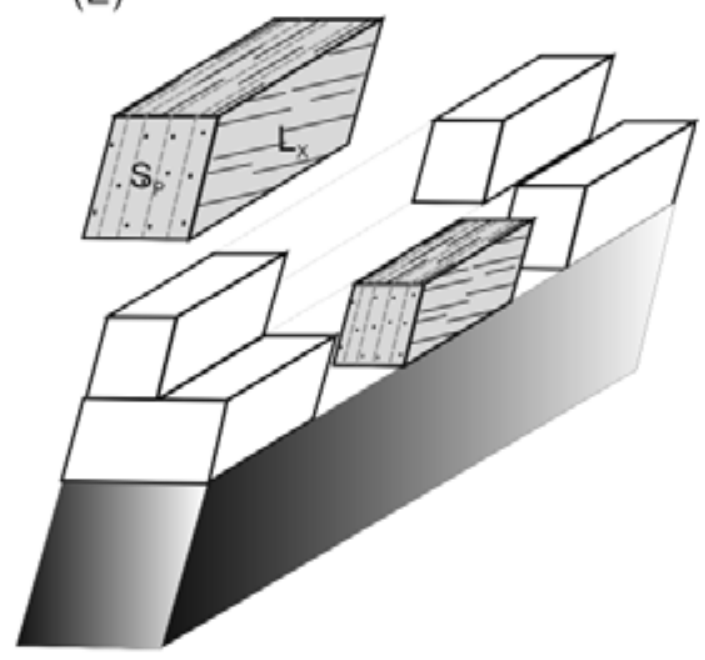

(F)

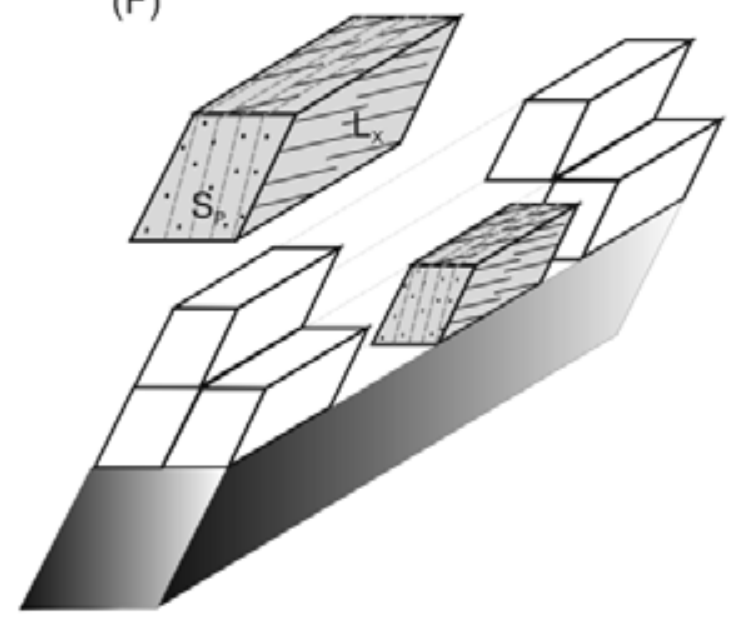

Figura 8. Fotografias de afloramentos da borda da Bacia de Camamu com tramas de simetria mineral (pseudo)ortorrômbica, monoclínica e triclínicas, suas correspondentes tramas de simetria de fraturamento reais $(A, B$ e $C$ ) e os modelos idealizados 3-D de blocos fraturados (D, E e F). Nas fotografias e nos blocos idealizados, notar as relações espaciais entre as foliações principais - $S_{P}$ representadas pelas superfícies $C$, as lineações de estiramento mineral - $L_{X}$ (indicadas pelas setas) $e$ as familias de falhas e fraturas produzidas. As tramas de fraturamento tendem a acompanhar paralelamente ou ortogonalmente a $S_{P}$ quando a mesma for vertical e as $L_{X}$ quando as $S_{P}$ são horizontais (ver fraturas ortogonais a $L_{X+1}$ na fotografia B da figura 2). 


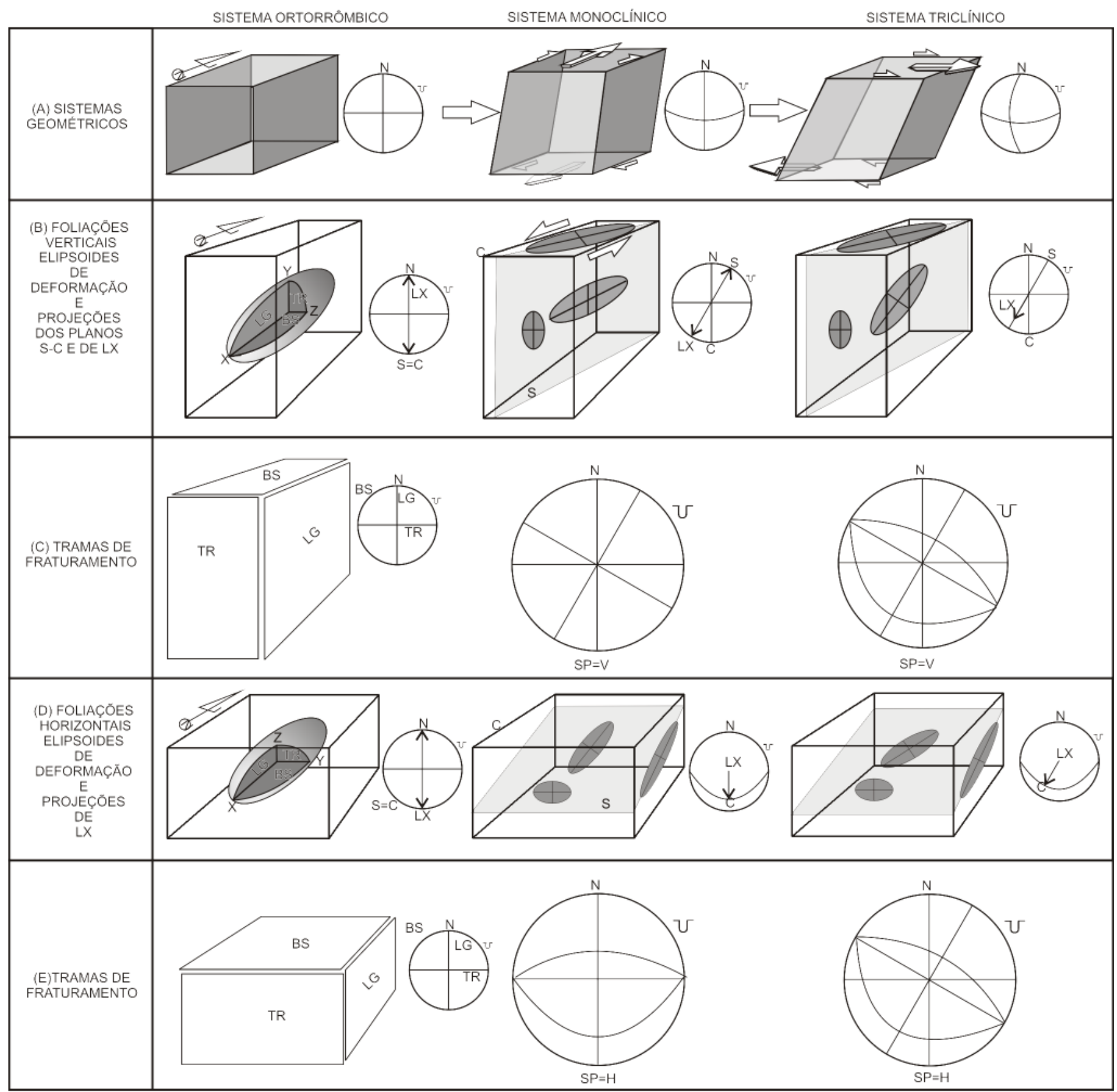

Figura 9 - Ilustrações (A) dos sistemas geométricos de simetria ortorrômbica, monoclínica e triclínica, em blocos diagramas e redes estereográficas igual-área, respectivamente. Representações 3-D em blocos diagramas e em redes estereográficas igual-área, das relações entre as superficies $S$ - $C$ e as $L_{X}$ e eixos do elipsoide de deformação, para os três sistemas de simetria mineral anteriores em situação de $S_{P}$ : verticais $(B)$ e horizontais (D). Representações 3-D e em rede estereográfica igual-área, das principais famílias de falhas geradas nos três sistemas de simetria mineral em situações de $S_{P}$ : vertical $(C)$ e horizontal $(E)$. $S=$ superficie $S, C=$ superficie $C, L_{X}=$ lineação de estiramento mineral. $L G=$ Fratura Longitudinal, $T R=$ Fratura Transversal e $B S=$ Fratura Basal. Essas situações geométricas foram modeladas levando em consideração o que foi observado no campo. Para maiores detalhes ler o texto.

e (ii) no caso com foliações horizontais a extensão pode procurar outras anisotropias mecânicas para se manifestar, nesse caso as $L_{X}$ (ver fotografia $B$ da figura 2).

Comparação entre os dados de estruturas de campo e os modelos de simetria mineral A comparação entre as orientações coletadas no campo dos planos de falhas e fraturas, das $\mathrm{S}_{\mathrm{P}}$ e $\mathrm{L}_{\mathrm{X}}$, e as obtidas a partir dos modelos geométricos de tramas de simetria, permite perceber que, praticamente todos os planos reais, sejam eles verticais ou horizontais, aparecem contemplados nos modelos. Levando em consideração que os planos de $\mathrm{S}_{\mathrm{P}}$ subverticais 
são muito mais frequentes que os sub-horizontais, que as $\mathrm{L}_{\mathrm{X}}$ são sub-horizontais, e que as orientações das direções das $\mathrm{S}_{\mathrm{p}}$ e das $\mathrm{L}_{\mathrm{x}}$ pode variar de $\mathrm{N}^{\circ} 0^{\circ}$ até $\mathrm{N} 30^{\circ}$, é possível entender a presença marcante de planos de falhas subverticais orientados próximos a $\mathrm{N}^{\circ}, \mathrm{N}^{\circ} 0^{\circ}$ e $\mathrm{N} 120^{\circ}$, não apenas como resposta às orientações dos campos remotos de tensão. Também é possível notar uma estreita combinação de tramas de simetria mineral monoclínicas e triclínicas, mais frequentes, e ortorrômbicas, comparando os gráficos de falhas com os de $\mathrm{S}_{\mathrm{P}}$ e $\mathrm{L}_{\mathrm{X}}$ (Figs. 4, 5, 6 e 8). Em adição a isso, nas figuras 1 e 3 nota-se que importantes orientações regionais de lineamentos estruturais do embasamento cristalino podem ser encontrados também no interior da bacia, indicando que estruturas rúpteis mais antigas podem ter sido também herdadas durante o rifteamento. Isso conduz à constatação de que na área estudada, três fatores mecânicos foram importantes na formação da BC e das "fábricas de fraturamento" associadas: (i) as tramas dúcteis planares e lineares das rochas do embasamento cristalino, (ii) os campos remotos de tensão e suas respectivas orientações, e (iii) estruturas rúpteis pretéritas reativadas.

Com base no que foi observado no campo, no que consta da literatura sobre a evolução tectônica da área e no que foi modelado geometricamente, uma sucessão de eventos pode então ser sugerida na formação das tramas de fraturamento da área de influência da Bacia de Camamu (Fig. 10):

(1) para ter havido a exposição de litotipos da fácies granulito, uma camada de crosta de $20-30 \mathrm{~km}$ deve
(1) DESCOMPRESSÃO LITOSTÁTICA 3-D + EROSĀO

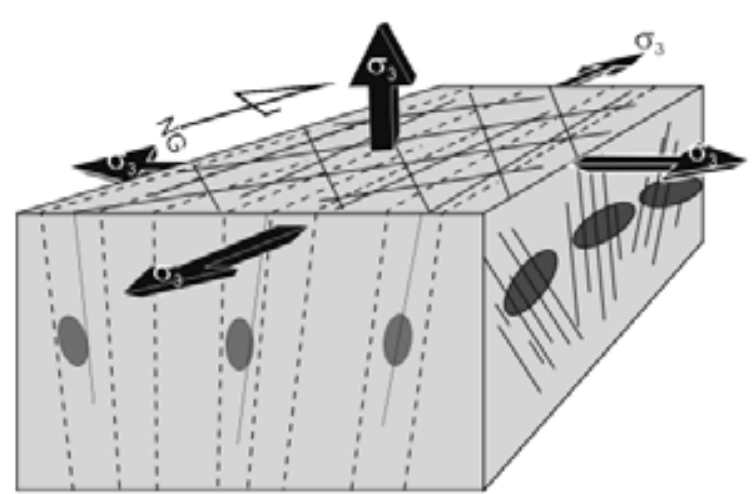

(4) EXTENSÃO NE-SW, $\sigma_{1}$ horizontal

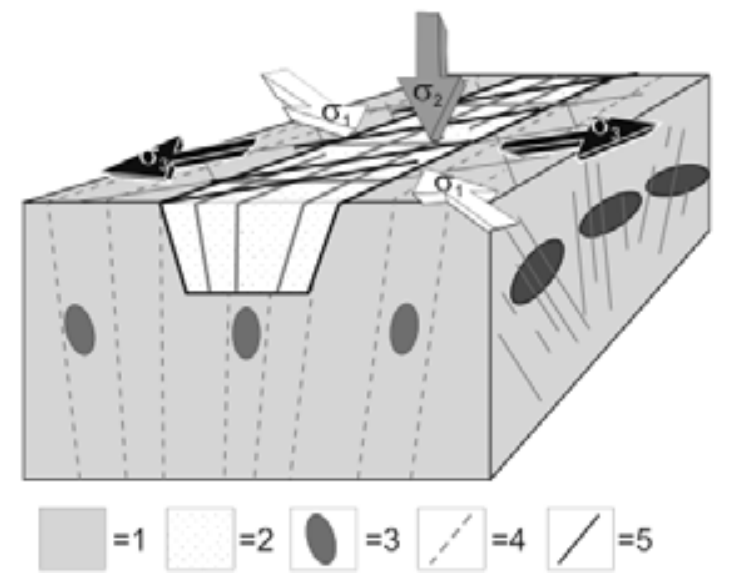

\section{(2 e 3) EXTENSÓES ORTORRÔMBICAS 3-D $\mathrm{N}-\mathrm{S} / \mathrm{E}-\mathrm{W}$ e NW-SE/NE-SW \\ $\sigma_{1}$ vertical, $\sigma_{1}>\sigma_{2}=\sigma_{3}$}

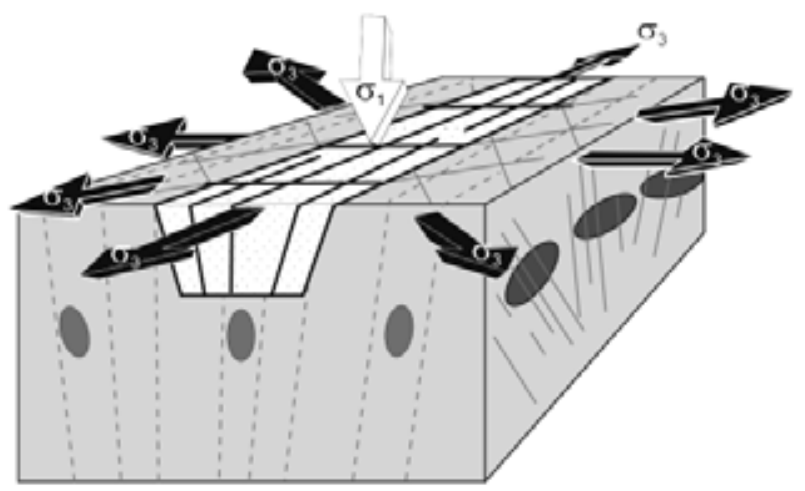

(5) EXTENSÃO NW-SE, $\sigma$, horizontal

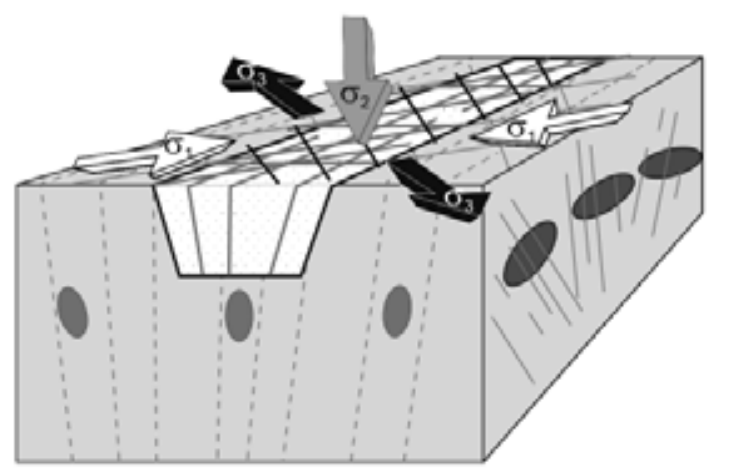

Figura 10. Blocos diagramas esquemáticos da evolução tectônica sugerida para a área de influência da Bacia de Camamu, com a orientação dos tensores principais e das principais estruturas produzidas no embasamento, em eventos pré-rifteamento, e na geração da BC. Em (A) a descompressão litosférica causa o relaxamento crustal e amplia a importância de estruturas dúcteis e rúpteis pretéritas do embasamento, em (B) durante as fases de extensão ortorrômbica, com $\sigma_{1}$ vertical, são geradas falhas E-W/ESE-WNW e N-S/NNE-SSW, em (C) e (D) nas fases transextensivas as falhas de transferência acompanham a orientação dos tensores principais mínimos, $N 40^{\circ}$ e N12 $0^{\circ} . S_{P}=$ superficie principal, ZCIIC e ZCP = lineamentos estruturais paralelos aos sistemas de falhas das Zonas de cisalhamento de Itabuna-Itaju do Colônia e Potiraguá, 1= embasamento cristalino, 2 = cobertura sedimentar, 3 = elipse de deformação, $4=$ traço da $S_{P}$ e $5=$ falha e fratura. 
ter sido removida, essa remoção, pode ter ocorrido lentamente e/ou ter sido acelerada pela presença de anomalias termais, implicando em um considerável relaxamento litosférico, cujo efeito sobre as rochas foi o de expandir descontinuidades mecânicas pré-existentes impressas nas tramas minerais dúcteis e nos sistemas antigos de falhas,

(2 e 3) com $\sigma_{1}$ vertical, durante os eventos tectônicos cedo- a sin-rifteamento, aconteceram duas fases de extensão ortorrômbica 3-D, com magnitudes de $\sigma_{2} \cong \sigma_{3}$, a primeira incentivando a produção e/ou reaproveitamento de falhas, com cinemáticas normais predominantes, N-S e E-W e a segunda NNE-SSW e ESE-WNW - respectivamente paralelas a subparalelas e perpendiculares a sub-perpendiculares ao comprimento maior da $\mathrm{BC}$, com reativação-formação de falhas normais paralelas às respectivas extensões, e

(4 e 5) com $\sigma$ horizontal, durante as fases mais avançadas de rifteamento, houve uma mudança na orientação do campo de tensão regional, com extensões regionais $\left(\sigma_{3}\right)$ acontecendo segundo orientações NW-SE, reativando falhas WNW-ESE, e NE-SW, reativando falhas NNE-SSW.

CONCLUSÃO As principais famílias de falhas do embasamento e das bordas da Bacia de Camamu são paralelas a subparalelas à foliação principal, $\mathrm{S}_{\mathrm{p}}$, subvertical do embasamento, $\mathrm{N} 00^{\circ}$, com variações de $\mathrm{N}^{\circ} 0^{\circ}$ a $\mathrm{N} 30^{\circ}$, e diagonais a esta, $\mathrm{N} 90^{\circ}$ a N $120^{\circ}$. O fato dos mergulhos da $S_{p}$ serem subverticias tanto para $E$ quanto para $\mathrm{W}$ deve ter facilitado a abertura do rifte de Camamu. Uma combinação entre a presença de falhas antigas e das orientações das extensões regionais $\left(\sigma_{3}\right) \mathrm{N}-\mathrm{S} / \mathrm{E}-\mathrm{W}$ e NW-SE/NE-SW e das tramas mineral do embasamento, deve ter facilitado a geração de falhas $\mathrm{N} 00^{\circ}, \mathrm{N} 30^{\circ}, \mathrm{N} 90^{\circ}$ e N120 . Não somente as $\mathrm{S}_{\mathrm{p}}$, mas também as $\mathrm{L}_{\mathrm{X}}$ (principalmente quando as $S_{p}$ são sub-horizontais) tiveram papel importante na orientação espacial das falhas da BC.
As principais tramas de fraturamento observadas foram: (i) monoclínica a triclínica, as mais frequentes, onde as relações entre superfícies S-C são menos estreitadas ou houve sobreposição de fases de deformação, e (ii) ortorrômbica, em zonas de cisalhamento de deformação muito intensa onde as $\mathrm{S}_{\mathrm{P}}$ e as $\mathrm{L}_{\mathrm{X}}$ tendem a se tornar paralelas. Tanto estruturas planares paralelas quanto ortogonais, quanto às $\mathrm{S}_{\mathrm{p}}$ e $\mathrm{L}_{\mathrm{X}}$, foram geradas.

Em suma, o estudo apresentado conduz à constatação de que na borda oeste da Bacia de Camamu, não somente os campos remotos de tensão, mas também as fábricas dúcteis planares e lineares e rúpteis antigas das rochas do embasamento cristalino adjacente, controlaram de forma marcante a formação e a evolução tridimensional das falhas/fraturas durante a extensão relacionada ao rifteamento continental que originou a bacia em foco.

Assim, utilizando dados de estruturas de campo, acredita-se que esse trabalho tenha contribuído para: (i) preencher uma lacuna importante sobre a influência da herança de estruturas do embasamento na formação e evolução de bacias sedimentares tipo rifte, (ii) caracterizar e conceituar o termo "trama de fraturamento" em rochas do embasamento e de bacias sedimentares, e (iii) reforçar a influência das estruturas lineares, e não somente planares, dúcteis na construção da trama de fraturamento nestes litotipos.

Agradecimentos Os dados desse trabalho foram obtidos através do projeto "Neotectônica Litorânea do NNE do estado da Bahia," coordenado por LCCG e financiado pelo CNPq (processo $\mathrm{n}^{\circ} 472355 / 2004-0$ ). LCCG, SCC e JFSB agradecem também ao CNPq pelas bolsas de produtividade em pesquisa - PQ. Os agradecimentos finais vão para os revisores da RBG pelas valiosas modificações sugeridas que ajudaram a enriquecer esse manuscrito.

\section{Referências}

Allen P.A. \& Allen J.R. 2005. Basin Analysis. Principles and Applications. 2.ed., Oxford, Blackwell Publishing, 560 p.

Almeida F.F.M. 1977. Cráton do São Francisco. Revista Brasileira de Geociências, 7:349-364.

Asmus H.E. \& Porto R. 1980. Diferenças nos estágios iniciais da evolução da margem continental brasileira: possíveis causas e implicações. In: SBG, Congresso Brasileiro de Geologia, 31, Anais, p. 225-239.

Barbosa J.F.S. \& Dominguez J.M.L. (eds.) 1996. Mapa Geológico do Estado da Bahia. Salvador, Secretaria da Indústria Comércio e Mineração/Superintendência de Geologia e Recursos Minerais, Texto Explicativo, 400 p.

Barbosa J.S.F. \& Sabaté P. 2004. Archean and Paleoproterozoic crust of the São Francisco Cráton, Bahia, Brazil: Geodynamic features. Precambrian Research, 133:1-27.

Barbosa J.S.F. \& Corrêa-Gomes L.C. (eds.) 2003. I Workshop sobre o Orógeno Itabuna-Salvador-Curaçá - I WOISC.
Geologia e guias de excursão de campo. Revista Brasileira de Geociências, 33(1-Suplemento):1-88.

Barbosa J.F.S, Corrêa-Gomes L.C., Dominguez J.M.L, Souza Cruz S.A.S., de Souza J.S.S. 2005. Petrografia e Litogeoquimica das Rochas da Parte Oeste do Alto de Salvador, Bahia. Revista Brasileira de Geociências, 35(4 - Suplemento):9-22

Caixeta J.M., Milhomem P.S., Witzke R.E., Dupuy I.S.S., Gondijo G.A. 2007. Bacia de Camamu. Boletim de Geociências da Petrobras, 15(2):455-461.

Castro Jr. A.C.M. 1987. The northeast Brazil and Gabon basins: A double rifting system associated with multiple detachment surfaces. Tectonics, 6:727-738.

Clifton E.A., Schlische R.W.,Withjack M.O., Ackermann R.V. 2000. Influence of rift obliquity on fault-population systematics: results of experimental clay models. Journal of Structural Geology 22:1491-1509.

Conceição H. \& Otero O.M.F. 1996. Magmatismo granítico 
e alcalino no estado da Bahia. Uma epítome do tema. Salvador, SICM/SGM/PPPG/UFBA, 133 p.

Corrêa Gomes L.C., Tanner de Oliveira M.A.F., Motta A.C., Cruz M.J.M. (eds.) 1996. Províncias dos diques máficos do Estado da Bahia. Mapa, evolução temporal e estágio atual do conhecimento. Salvador, SICM/SGM/PPPG/ UFBA, $144 \mathrm{p}$.

Corrêa-Gomes L.C., Dominguez J.M.L., Barbosa J.S.F., Silva I.C. da. 2005a. Padrões de orientações dos campos de tensão, estruturas, herança do embasamento e evolução tectônica das Bacias de Camamu e porção Sul do Recôncavo, Costa do Dendê, Bahia, Brasil. Revista Brasileira de Geociências, 25(4):34-45.

Corrêa-Gomes L.C., Dominguez J.M.L., Barbosa J.S.F., Silva I.C. da, Pinto M.V. 2005b. Relações entre Orógenos, Zonas de Cisalhamento, Quebra continental e Deformações 3-D. A história tectônica da Bacia sedimentar de Almada, Bahia, Brasil. Revista Brasileira de Geociências, 25(4):23-33.

Davis G.H. 1984. Structural Geology of Rocks and Regions. New York, John Wiley \& Sons Inc., 492 p.

Destro N. 2002. Falhas de Alivio e de Transferência: $O$ significado Tectônico e Econômico no Rifte do RecôncavoTucano-Jatobá, NE Brasil. Tese de Doutorado, Universidade Federal de Ouro Preto, Ouro Preto, 173 p.

Destro N., Szatmari P., Alkmim F.F., Magnavita L.P. $2003 a$. Release faults associated structures, and their control on petroleum trends in the Reconcavo rift, northeast Brazil. AAPG Bulletin, 87(7):1123-1144.

Destro N., Alkmin F.F., Magnavita L.P., Szatimari P. 2003 b. The Jeremoabo transpresional transfer fault, ReconcavoTucano rift, NE Brazil. Journal of Structural Geology, 25:1263-1279.

Donath F.A. 1970. Some information squeezed out of rock. Amer. Science, 58:54-72.

Duyster J.P. 2000. StereoNet for Windows. Cornell University, http://homepage.ruhr-uni-bochum. de/ Johannes.P.Duyster/stereo/stereo1.htm.

Griggs D.T. 1967. Hydrolytic weakening of quartz and other silicates. Geophys. J. R. Astron. Soc. 14:19-31.

Griggs D.T. \& Handin J. 1960. Observations on fracture and a hypothesis of earthquakes. In: Griggs D.T., Handin J., (eds.), Rock Deformation. Geol. Soc. Am. Mem., 79:347-373.

Griggs D.T., Turner F.J., Heard H.C. 1960. Deformation of rocks at $500^{\circ}$ to $800^{\circ} \mathrm{C}$. In: Griggs, D.T., Handin, J. (eds.), Rock Deformation. Geol. Soc. Am. Mem. 79:39-104.

Handin J., Hager R.V., Friedman M., Feather J.N. 1963. Experimental deformation of sedimentary rocks under confining pressure: pore pressure tests. Am. Assoc. Pet. Geol. Bull. 47:718-755.

Heard H.C. 1960. Transition from brittle fracture to ductile flow in Solenhofen limestone as a function of temperature, confining pressure, and interstitial fluid pressure. In: Griggs, D.T., Handin, J. (eds.), Rock Deformation. Geol. Soc. Am. Mem. 79:193-226.

Heard H.C. 1963. Effect of large changes in strain rate in the experimental deformation of Yule marble. J. Geol. 71:162- 195.

Heard H.C. \& Raleigh C.B. 1972. Steady-state flow in marble at $500^{\circ} \mathrm{C}$ to $800^{\circ}$ C. Geol. Soc. Am. Bull., 83:935-956.

Hobbs B.E., Means W.D., Williams P.F. 1976. An Outline of Structural Geology. New York, John Wiley \& Sons Inc., $512 \mathrm{p}$.

Magnavita L.P. 1992. Geometry and kinematics of the Recôncavo-Tucano-Jatobá rift, NE, Brazil. Tese de Doutorado, University of Oxford, Oxford, 493 p.

Magnavita L.P. 1993. Reativação do embasamento Précambriano durante a abertura cretácea do rift do Recôncavo - Tucano - Jatobá, NE Brasil. In: SBG, Simpósio sobre o Cráton do São Francisco, 2, Anais, p. 222-230.

Magnavita L.P., Silva R.R. da, Sanches C.P. 2005. Guia de campo da Bacia do Recôncavo, NE do Brasil. Boletim de Geociências da Petrobras, 13(2):301-334.

Milani E.J. \& Davison I. 1988. Basement control and transfer tectonics in the Recôncavo - Tucano -Jatobá rift, Northeast Brazil. Tectonophysics, 154:41-70.

Nagaraj T.S. 1993. Principles of Testing Soils, Rocks and Concrete. Elsevier, Amsterdam.

Paterson M.S. 1958. Experimental deformation and faulting in Wombeyan marble. Geol. Soc. Am. Bull., 69:465-476.

Paterson M.S. \& Weiss L.E. 1961. Symmetry concepts in the Structural analysis of deformed rocks. Geol. Soc. Amer. Bull., 72:843-882.

Paterson M.S. \& Wong T-F. 2005. Experimental Rock Deformation. The Brittle Field. 2.ed., New York, Springer Verlag, 348 p.

Silva I.C. 2009. Evolução Dinâmica da Bacia de Camamu, Bahia, Brasil. Dissertação de Mestrado, Instituto de Geociências, Universidade Federal da Bahia, Salvador, $108 \mathrm{p}$.

Twiss R.J. \& Moores E.M. 2006. Structural Geology. 2.ed., New York, W.H. Freeman and Company, 736 p.

Ussami N., Karner G.D., Bott M.H.P. 1986. Crustal detachment during South Atlantic rifting and formation of Tucano-Gabon basin system. Nature, 322:629-632.

van der Pluijm B.A. \& Marshark S. 2004. Earth Structure. An Introduction to Structural Geology and Tectonics. 2.ed., New York, W.W. Norton, 656 p.

Zoback M.D. 1992. First- and Second-Order Patterns of Stress in the Litosphere: The World Stress Map Project. Journal of Geophysical Research, 97(B8):11.703-11.728.

Manuscrito ID 15798

Submetido em 23 de outubro de 2009 Aceito em 04 de outubro de 2011 